\title{
NEUTRALIZATION OF EDEMA, HEMORRHAGE AND MYONECROSIS INDUCED BY NORTH \\ AMERICAN CROTALID VENOMS \\ IN SIMULATED FIRST-AID \\ TREATMENTS
}

\author{
By \\ JASON EVANS \\ Bachelor of Science \\ Oklahoma State University \\ Stillwater, Oklahoma \\ 1996 \\ Submitted to the Faculty of the \\ Graduate College of the \\ Oklahoma State University \\ in partial fulfillment of \\ the requirements for \\ the Degree of \\ MASTER OF SCIENCE \\ December, 1997
}


NEUTRALIZATION OF EDEMA, HEMORRHAGE

AND MYONECROSIS INDUCED BY NORTH

AMERICAN CROTALID VENOMS

IN SIMULATED FIRST-AID

TREATMENTS

Thesis Approved:

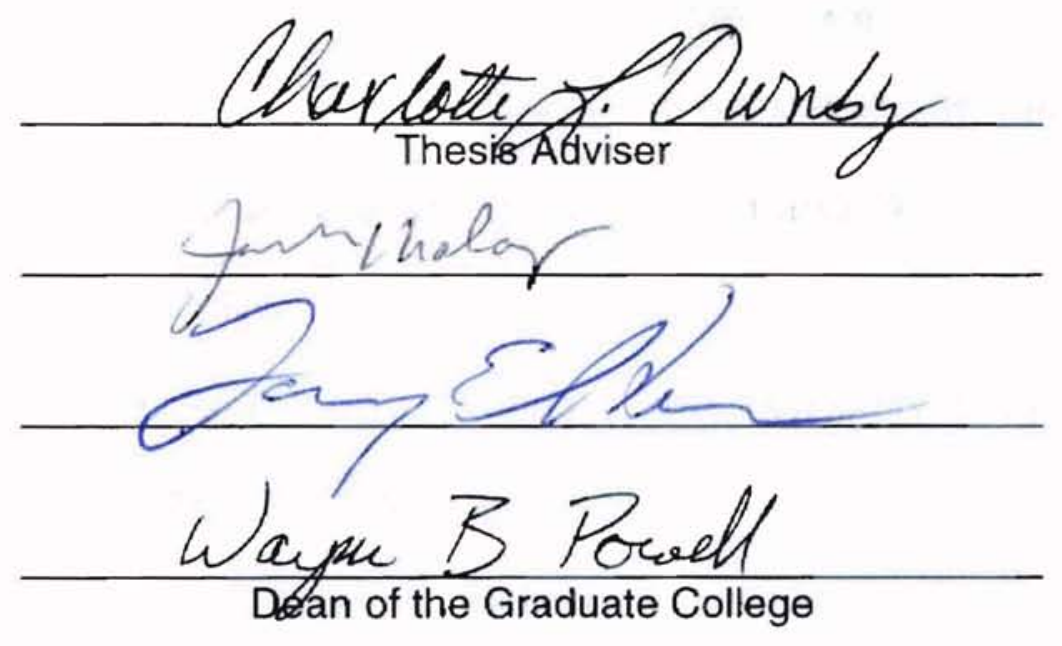




\section{ACKNOWLEDGMENTS}

I would like to express my most sincere thanks to Dr. Charlotte Ownby for all of her patience, guidance and expertise above and beyond the call of duty during the completion of this project. Dr. Ownby is a friendly, warm-hearted person with a sense of humor and zest that could always prompt a smile, even in the face of miserable data. She has found that ever-elusive balance between levity and hard work that is truly the key to success. Her dedication to family, science and cats has provided me a wonderful role model with which I hope to continue my pursuits in science and in life. I would also like to thank Dr. Larry Stein and Dr. Jerry Malayer for their willingness, dedication and support of my scientific endeavors in the both Graduate and Veterinary programs. Their teachings, both in and out of the classroom, have challenged me to pursue

excellence into the next century of medicine and research. To Terry Colberg, I would especially like to thank you for allowing me to invade your lab and tolerating the novice spilling your reagents. Your patience and efforts for showing me the finer points of laboratory management and technique are greatly appreciated.

I would also like to extend special thanks to the Class of 1999 for all of the support and encouragement they have given me for my alternative studies during the first two years of the veterinary program. I am very lucky to be 
associated with such a wonderful group of future doctors. And to Cathy Yates, my dear classmate, colleague, and partner in crime, I hope that all of your dreams come true. I could not have done any of it without your friendship.

Finally, I wish to thank my mother and stepfather, Bruce and Sherry Pierce, and my father, Robert J. Evans, jr., who first inspired me to seek the joys of education and of life. Your love and sacrifice can never be adequately repaid in words of gratitude. I could not even begin to describe how much your pride in me means. 


\section{TABLE OF CONTENTS}

Chapter Page

$\begin{array}{ll}\text { I. LITERATURE REVIEW } & 1\end{array}$

Occurrence of snakebites $\quad 1$

Treatment of snakebites 3

Common sequelae of Crotalid envenomation $\quad 10$

Evaluation of degree of envenomation $\quad 11$

$\begin{array}{ll}\text { Antivenom } & 12\end{array}$

Complications of antivenom therapy 16

$\begin{array}{ll}\text { Controversial treatments of Crotalid envenomation } & 19\end{array}$

Research for effective first-aid therapy 22

Components of snake venom 23

Myotoxic action of venom 24

Hemorrhagic action of venom $\quad 30$

ACL and CVV venom 32

II. ABSTRACT AND INTRODUCTION 35

III. MATERIALS AND METHODS 40

$\begin{array}{ll}\text { IV. RESULTS } & 48\end{array}$

$\begin{array}{ll}E_{50} \text { dose-response curves } & 48\end{array}$

In vitro neutralization $\quad 48$

In vivo neutralization $\quad 49$

$\begin{array}{ll}\text { V. DISCUSSION } & 67\end{array}$

$\begin{array}{ll}\text { REFERENCES } & 80\end{array}$ 


\section{LIST OF TABLES}

Table

Page

1. Annual deaths caused by snakebites

2. Common Crotalid snakes of North America 4

3. Common signs of snake poisoning 9

4. Degree of envenomation and antivenom dosage 13

5. Composition of Crotalid venom 25

$\begin{array}{ll}\text { 6. Classification of myotoxins } & 27\end{array}$

7. Some toxic PLA $A_{2}$ in Crotalid venom 29 


\section{LIST OF FIGURES}

$\begin{array}{lll}\text { Figure } & \text { Page }\end{array}$

1. ACL dose-response experiments 52

2. CVV dose-response experiments 53

3. In vitro neutralization of edema 54

4. In vitro neutralization of hemorrhage 55

5. In vitro neutralization of myonecrosis 56

6. In vivo neutralization of edema with topical DMSO-p-BPB 57

7. In vivo neutralization of hemorrhage with topical DMSO-p-BPB 58

8. In vivo neutralization of myonecrosis with topical DMSO-p-BPB 59

9. In vivo neutralization of edema with i.m. saline-p-BPB 60

10. In vivo neutralization of hemorrhage with i.m. saline-p-BPB 61

11. In vivo neutralization of myonecrosis with i.m. saline-p-BPB 62

12. In vivo neutralization of edema with i.p. antivenom 63

13. In vivo neutralization of hemorrhage with i.p. antivenom 64

14. In vivo neutralization of myonecrosis with i.p. antivenom 65 


\section{NOMENCLATURE}

$\begin{array}{ll}\text { ACL } & \text { Agkistrodon contortrix laticinctus } \\ \text { CVV } & \text { Crotalus viridis viridis } \\ \text { p-BPB } & \text { parä-Bromophenacyl bromide } \\ \text { DMSO } & \text { Dimethyl sulfoxide } \\ \text { Ax } & \text { Wyeth's antivenom } \\ \text { PSS } & \text { Physiologic saline }(0.90 \% \mathrm{NaCl}) \\ \text { i.m. } & \text { Intramuscular } \\ \text { i.v. } & \text { Intravenous } \\ \text { i.p. } & \text { Intraperitoneal } \\ \text { i.d. } & \text { Intradermal } \\ \text { CK } & \text { Creatine kinase } \\ \text { Hb } & \text { Hemoglobin }\end{array}$




\section{CHAPTER 1}

\section{LITERATURE REVIEW}

\section{Occurrence of venomous snakebites}

There are about one million venomous snakebites reported each year (Gonzalez, 1991) of which more than 30,000 are fatal (Tu, 1977; White, 1995; Warrell, 1996). Table 1 lists the approximate number of annual deaths around the world as a result of venomous snake encounters. The number of lethal incidents is higher in the less developed areas of the world due to increased encounters and decreased use of effective antivenom treatments (Underwood, 1979; Warrell and Fenner, 1993). In the United States, the number of annual venomous snakebite poisonings is roughly 8,000 with less than one half of one percent being fatal (Gomez and Dart, 1995). The 9 to 14 yearly fatalities typically occur in small children and persons over 70 years of age, especially with poorly handled medical treatment (Russell, 1996; Warrell, 1996). The vast majority of these bites are due to species within the Viperidae sub-family Crotalinae (Litovitz et al., 1991; Gomez and Dart, 1995). Representative species in this sub-family include the Western Diamondback rattlesnake (Crotalus atrox), the Prairie Rattlesnake (Crotalus viridis viridis) and the Broad-banded Copperhead (Agkistrodon contortrix laticinctus). Most of the serious bites, 
TABLE 1

\section{ESTIMATES OF ANNUAL MORTALITY FROM SNAKEBITES}

\begin{tabular}{lr}
\hline Region & No. of deaths \\
\hline Asia & $25,000-35,000$ \\
South America & $3,000-4,000$ \\
North America and Mexico & $300-500$ \\
Europe & 50 \\
Oceania & 10 \\
Africa & $400-1,000$ \\
Total & $\mathbf{3 0 , 0 0 0 - 4 0 , 0 0 0}$ \\
\hline
\end{tabular}

Swaroop \& Grab (1954) 
though, are caused by rattlesnakes (Parrish, 1965; Gomez and Dart, 1995;

Russell, 1996; Warrell, 1996). Russell (1996) found that over 60 percent of envenomations in the United States were caused by Crotalus and Sisturus, the two genus of rattlesnakes, slightly more than 21 percent for Agkistrodon (copperhead and cottonmouth) species and less than 1 percent as a result of Elapid (coral snake) encounters. This literature review will concentrate on the composition of crotalid venom and treatment of crotalid envenomations. It will not cover other members of the Viperidae family, such as the true vipers, nor the Elapids (cobras and mambas) or Hydrophids (sea snakes). Table 2 lists the scientific and common names of some representative species from the family Crotalidae in North America.

\section{$\underline{\text { Treatment of venomous snakebites }}$}

The literature covering the treatment of venomous snakebites around the world is not only quite extensive, but also very similar in content. This review therefore covers primarily topics specifically referring to North American or Crotalid envenomation and treatment. Other references outside this parameter are cited only where applicable. The theories behind treatment of venomous snakebites are as old as recorded history, and have roots in both folk and contemporary medicine. Such folk and modern treatments have been thoroughly 
TABLE 2

PRINCIPAL VENOMOUS SNAKES OF THE UNITED STATES

Scientific Name

\section{Crotalus}

C. adamanteus

C. atrox

C. cerastes

C. c. cerastes

C. horridus

C. mitchellii

C. ruber

C. scutulatus

C. viridis

C. v. viridis

Sistrurus

S. catenatus

S. miliarius

S. m. barbouri

S. m. steckeri

Agkistrodon

A. contortrix

A. c. contortrix

A. c. laticinctus

A. piscivorus

A. p. piscivorus
Common Name

Rattlesnake

Eastern Diamondback

Western Diamonback

Sidewinder

Sonoran Sidewinder

Timber Rattlesnake

Speckled Rattlesnake

Red Diamond Rattlesnake

Mohave Rattlesnake

Western Rattlesnake

Prairie Rattlesnake
Original Describer

Linnaeus, 1758

Palisot de Beauvois, 1799

Baird and Girard, 1853

Hallowell, 1854

Hallowell, 1854

Linnaeus, 1758

Cope, 1861

Cope, 1892

Kennicott, 1861

Rafinesque, 1818

Rafinesque, 1818
Pigmy Rattlesnakes \& Massasauga
Massasauga
Pigmy Rattlesnake
Dusky Pigmy Rattlesnake
Western Pigmy Rattlesnake

Copperhead \& Cottonmouth

Copperhead

Southern Copperhead

Broad-banded Copperhead

Cottonmouth

Eastern Cottonmouth
Garman, 1883

Rafinesque, 1818

Linnaeus, 1758

Gloyd, 1935

Gloyd, 1935

Palisot de Beauvois, 1799 Linnaeus, 1766

Linnaeus, 1766

Gloyd and Conant, 1934

Lacepede, 1789

Lacepede, 1789

Gomez and Dart (1995) 
described elsewhere, but Gomez and Dart (1995) and Russell (1996) provide an adequate review of recent snakebite treatment literature. The primary goal of medical treatment is to reduce mortality and morbidity. Recent medical advances, particularly the improved production and use of antivenom, have lowered the aiready small number of snakebite related deaths (Parrish, 1965; Russell, 1983; Russell, 1996). However, the prevalence of local tissue damage, despite the use of antivenom or other therapy, remains an issue of medical concern (Ownby et al., 1983; Lomonte et al., 1993; Rucavado and Lomonte, 1996).

Traditional folk remedies are often more ritualistic than they are practical, as the use of poultices, bandages, herbs, teas or primitive incisions and suction of the affected area do little more than give peace of mind to the victim. Modern medicine is only slightly more effective at reducing the local tissue damage caused by snake venom. The practice of cryotherapy, fasciotomy, tourniquets, electro-shock therapy and other modern techniques have not only been shown to be ineffective, but are also not recommended (Gomez and Dart, 1995; Russell, 1996). The recommended first-aid listed by Gomez and Dart (1995) and Russell (1996) include: (1) retreat out of the striking distance of the snake, (2) reassure the victim; try to keep calm. (3) immobilize the limb or affected region, and (4) transport the victim to a medical facility as soon as possible. Ice, tourniquets or other constrictive bands, food or fluids, and any primitive techniques which cause potential harm, such as excision therapy, are contraindicated. Many of the firstaid and hospital techniques, both past and present, are performed out of the 
urgency that something must be done. Such practices may ease the mind of the patient, but they often do more harm than good. To date, the only truly effective treatment for snakebites is the use of antivenom (Wingert, 1991; Meier, 1995; White, 1995). The possibility of other effective treatments for snakebites is currently under investigation.

The first-aid procedures listed by most authors necessitate the immobilization of the victim, and the transport of the patient to a hospital as quickly as possible. First-aid should not substitute for treatment at a medical facility. One of the most important aspects of the prehospital scenario is to calm the snakebite victim. Warrell (1996) describes how anxiety following a bite can potentiate those signs common to envenomation. Reassurance from bystanders emphasizing that most bites are not fatal aids in keeping the victim's physical mobility at a minimum. The other important consideration of the prehospital stage is to "do no harm" (Hardy, 1992; White, 1995). The application of tourniquets, or other constricting bands, the use of ice and the practice of excision therapy (the "cut and suck" method) should never be attempted, especially by the layperson (Gomez and Dart, 1995; Russell, 1996). A 1984 committee meeting of the American Association of Poison Control Centers and the American College of Physicians also decided that such primitive practices are to be discouraged (Wingert, 1991; Gold, 1996). White (1995) also adds that no food or oral fluids, especially alcohol, should be given. The only prehospital treatment that is acceptable is the establishment of an intravenous access and the administration of oxygen, if necessary (Gomez and Dart, 1995). While the 
guidelines of immobilization of the affected region, urgency to reach a medical facility and "do no harm" are fairly constant throughout the literature, some slight variations in first-aid protocol do exist. Russell (1996) favors the cleansing of the envenomated region with soap and water, but White (1995) advises against major cleaning techniques. Gold (1996) also stipulates the use of negative pressure devices if used within the first five minutes after the bite. This approach does not violate the "do no harm" rule, as it does not advocate incisions made by the layperson. However, White (1995) discourages the application of any kind of suction to the wound.

The ultimate goal of the medical treatment protocol is controlling shock, neutralizing venom action, and preventing secondary infection. Gomez and Dart (1995), Russell (1996) and Wingert (1991) also provide excellent reviews of hospital procedures. Once at the medical facility, the patient must first be evaluated for any immediate life-threatening conditions, such as hypovolemic shock or respiratory failure. Medical staff should also consider treating any firstaid attempts, such as tourniquets, that have been inappropriately performed or that may hinder further therapy. Care should be taken when removing any tourniquets, as the sudden flow of blood may induce shock, and should only be performed after an intravenous access has been established (Gomez and Dart, 1995). Russell (1996) recommends gradually applying bands of less and less constriction prior to removing a tightly bound tourniquet. The timing of any subsequent treatment, namely antivenom therapy, becomes the judgment of trained medical personnel. Only when the snakebite victim is stable can medical 
personnel truly assess the severity of the envenomation or consider further treatment.

The course of further treatment depends on a number of factors, particularly the species of snake involved in the envenomation and the severity of the bite (Wingert, 1991; Gomez and Dart, 1995; Russell, 1996). The type of snake involved in the bite is important to determine since different species' venoms induce different types of damage. For example, the major symptom of Crotalid envenomation is local tissue damage, possibly to the point of complete dysfunction (Mebs and Ownby, 1990; Lomonte, 1994; Warrell, 1996). The primary signs of Elapid envenomation are neurotoxic in nature (Gomez and Dart, 1995). A list of the most common symptoms of rattlesnake venom poisoning is provided in Table 3. Determination of the type of snake allows selection of the appropriate antivenom, if any, to be used in treatment. The severity of envenomation will then dictate not only the use of antivenom, but also the quantity of antivenom to be administered (Wingert, 1991; Russell, 1996; Theakston, 1996). Russell (1996) contends that antivenom need not be used in cases of minimal envenomation. In fact, nearly 25 percent of Crotalid bites do not result in envenomation (Wingert, 1991; Gomez and Dart, 1995; Russell, 1996). Wingert (1991), however, suggests that antivenom should be administered in cases of minimal envenomation for the true magnitude of bite 
TABLE 3

INCIDENCE OF SYMPTOMS OF RATTLESNAKE VENOM POISONING

\begin{tabular}{lclc} 
Symptom or Sign & Incidence & Symptom or Sign & Incidence \\
\hline & & & \\
Fang marks & $100 \%$ & Increased blood clotting time & $37 \%$ \\
Swelling and edema & $74 \%$ & Decreased hemoglobin & $37 \%$ \\
Weakness & $70 \%$ & Thirst & $36 \%$ \\
Pain & $65 \%$ & Necrosis & $27 \%$ \\
Numbness of tongue, mouth & $63 \%$ & Abnormal electrocardiogram & $26 \%$ \\
or scalp or feet & & Glycosuria & \\
Changes in pulse rate & $60 \%$ & Increase salivation & $20 \%$ \\
Numbness of affected part & $57 \%$ & Sphering of red blood cells & $20 \%$ \\
Faintness or dizziness & $57 \%$ & Proteinuria & $18 \%$ \\
Blood pressure changes & $54 \%$ & Cyanosis & $16 \%$ \\
Ecchymosis & $51 \%$ & Increased blood platelets & $16 \%$ \\
Sweating and/or chills & $43 \%$ & Hematemesis, hematuria, or & $16 \%$ \\
Nausea, vomiting or both & $42 \%$ & Mnelena & $15 \%$ \\
Changes in body temperature & $42 \%$ & Blurring of vision & $12 \%$ \\
Decreased blood platelets & $42 \%$ & Swollen eyelids & $12 \%$ \\
Fasciculations & $41 \%$ & Muscle contractions & $7 \%$ \\
Swollen regional lymph nodes & $40 \%$ & Retinal hemorrhage & $6 \%$ \\
Vesiculations & $40 \%$ & Convulsions & $5 \%$ \\
Respiratory rate changes & $40 \%$ & & $1 \%$ \\
& & & \\
\hline
\end{tabular}

Russell (1996) 
severity might be delayed. The theories and techniques of antivenom administration are covered later. The degree of envenomation is determined by the local signs, laboratory tests and systemic signs.

\section{Common sequelae of Crotalid envenomation}

In North America, in addition to the systemic effects, the most common sequelae of local tissue damage caused by envenomation by Crotalid species are edema, hemorrhage and myonecrosis (Mebs and Ownby, 1990; Rucavado and Lomonte, 1996; Gutierrez et al., 1996). Edema is thought to be associated with endothelial damage, with subsequent increases in vascular permeability leading to loss of plasma fluid into the affected region producing swelling (Wingert, 1991; Lloret and Moreno, 1993). Edema can also occur through the presence of exogenous autocoids in the venom, or by the release of endogenous autocoids induced by the venom (Lomonte, 1994). Erythema can also be associated with vasodilation and other alterations in vascular flow. Hemorrhage induced by snake venom is often the result of certain venom toxins causing adverse structural problems within the vascular endothelia (Bjarnason and Fox, 1988; Ownby, 1990). Red blood cells can then escape the vessels per rhexis or per diapedesis (Ownby, 1990; Lomonte, 1994). Petechia and ecchymosis are the most immediate identifying signs that hemorrhage is occurring (Wingert, 1991; Gomez and Dart, 1995; Russell, 1996; Warrell, 1996). Myonecrosis is the result of venom toxins directly disrupting the plasma membranes of the muscle cells (Ownby, 1990; Mebs and Ownby, 1990; Tu, 
1991; Lomonte, 1994). Myonecrosis can also occur indirectly via ischemia of the muscle mass produced by the disruption of blood flow to the region (Gutierrez and Lomonte, 1989; Ownby, 1990; Harris and Cullen, 1990). In this fashion, hemorrhagic toxins may contribute to the total myonecrosis (Ownby, 1990; Lomonte, 1994). The overall myotoxic effect is typically not seen grossly for several days to several weeks (Warrell, 1996). An overview of the specific toxins in snake venom that produce these effects is presented later.

\section{Evaluation of the degree of envenomation}

Though the various guidelines used to judge the severity of North American envenomations and recommendations as to the amount of antivenom to administer have been widely discussed in recent literature, Wingert (1991), Gomez and Dart (1995) and Russell (1996) provide a concise review. These medical descriptions are also listed in Table 4. The most common signs of envenomation are pain, swelling, hemorrhage and tissue loss, and generally occur in relation to the amount of venom injected (Wingert, 1991; White, 1995). Snakebites resulting in no or minor envenomation produce minor swelling and possibly occult hemorrhage that is limited to the site of the bite. Systemic signs are typically absent with no abnormal laboratory findings. Moderate envenomation includes edema and eccymosis that include a majority of the affected extremity. Systemic signs, such as nausea, vomiting, paresis and mild hypotension are typically present, but not life-threatening. Minor coagulation abnormalities of the blood may also be present. Severe envenomation includes 
signs of local tissue damage that involves the entire extremity and spread rapidly. Systemic anomalies are seen as dementia, paralysis, cardiac arrhythmias and possible respiratory failure. Coagulation is often severely impaired and urinalysis often reveals hematuria. White (1995) and Warrell (1996) also indicate the prevalence of renal failure in moderate to severe envenomation. Wingert (1991) also suggests the use of immuno-diagnosis in aiding to evaluate the severity of envenomation. Detection of specific levels of venom antigens in the victim's blood would provide a clearer picture as to how to treat a snakebite victim or how much antivenom to use (Riviere et al., 1997). At present, there are few studies regarding the detection of venom in the blood of snakebite victims, especially those involving Crotalids. Both moderate and severe envenomations warrant the use of antivenom.

\section{Antivenom}

A review of the description of antivenom and the antivenom producing process is provided by Chippaux and Goyffon (1991) and Dart and Horowitz (1996). Antivenom is animal serum, usually horse or sheep, that contains antibodies specific for the toxins found in snake venoms. It is made by injecting 
TABLE 4

\section{DEGREE OF ENVENOMATION AND ANTIVENOM TREATMENT REQUIREMENTS}

\section{Degree of Envenomation and Symptoms Vials of Antivenom (1 vial=10ml)}

No envenomation

Fang marks present with no local or systemic reactions

\section{Minimal envenomation}

$5-8$

Edema, erythema, ecchymosis limited to site of bite.

Minor systemic signs such as nausea, mild hypotension may

or may not be present

Coagulation parameters normal

\section{Moderate envenomation}

Edema, erythema, ecchymosis present in most of extremity

Systemic signs such as nausea, hypotension, tachycardia

and tachypnea present but not life threatening

Coagulation parameters may be abnormal with decreases in

both platelets and fibrinogen

Severe envenomation

$14-30$

Edema, erythema, ecchymosis involving entire extremity

Marked systemic signs such as dementia, hypotension,

respiratory distress present and may be life threatening

Coagulation parameters abnormal, with spontaneous bleeding,

and unmeasurable platelet and fibrinogen levels

Compiled from Wingert (1991), Gomez and Dart (1995) and Russell (1996) 
small amounts of venom from one or more species into an animal, thus producing a humoral response resulting in the formation of antibodies to the toxins. The serum from these animals can then be collected and administered to a snakebite victim, with the hope that the already formed antibodies will neutralize circulating venom toxins. Monovalent antivenom is made using venom from only one species while polyvalent antivenom is made using venom from two or more snake species. The final antivenom solution consists largely of the $\mathrm{F}\left(a b^{\prime}\right)_{2}$ regions of the immunoglobulins (Dart and Horowitz, 1996). Investigators have been using the $F\left(a b^{\prime}\right)_{2}$ fractions in order to not only increase the efficacy of the antivenom, but decrease potential adverse reactions to antivenom therapy, such as anaphylaxis and serum sickness. The idea is that by using smaller $\mathrm{F}\left(a b^{\prime}\right)_{2}$ region rather than the whole IgG molecule, the antivenom would be able to penetrate tissues faster (Dart and Horowitz, 1996; Consroe et al., 1996; Scherrmann and Pepin, 1996; Grandgeorge et al, 1996; Landon and Smith, 1996). Digesting the $\lg$ molecule above the disulfide bond with papain produces two separate Fab regions and a Fc domain, while dissolving the immunoglobulin below the disulfide bond with pepsin allows the two Fab fractions to remain attached as a $\mathrm{F}\left(\mathrm{ab}{ }^{\prime}\right)_{2}$ molecule. Riviere et al. (1997), though, demonstrated that the $F\left(a b^{\prime}\right)_{2}$ region provided greater venom neutralization than the smaller Fab molecule, as it causes a higher redistribution of venom into the vascular space. Venom is more effectively neutralized in the vascular compartment than in the extravascular space. 
Different regions of the world have different antivenoms, as they are made from the species found in that geographical location. The only Crotalid antivenom used in North America is Wyeth's Polyvalent Antivenin, which is made using the venoms of Crotalus atrox, Crotalus adamanteus, Crotalus durissus terrificus and Bothrops atrox (Wingert, 1991; Gomez and Dart, 1995). The common names of these species are Western Diamondback Rattlesnake, Eastern Diamondback Rattlesnake, South American Rattlesnake and Fer-delance, respectively.

A summary of the proper use and dosage of antivenom in snakebite therapy is given by Gomez and Dart (1995) and Russell (1996) and is presented in Table 4. The administration of Crotalid antivenom is based upon the degree of envenomation. Gomez and Dart (1995) state the recommended dose as 10 vials for moderate to severe envenomations and up to 20 vials in severe cases presenting with extensive hemodynamic abnormalities. Russell (1996) lists a range of 5 to 30 vials of antivenom for moderate to severe envenomation, respectively. Both authors suggest that the reconstituted antivenom should be administered as a $1: 10$ to $1: 15$ dilution by adding it to 500 to $1500 \mathrm{cc}$ of physiologic saline or crystalloid within the first few hours after the bite. Wingert (1991) also supports the previously described procedure for antivenom administration. These authors suggest that the first infusions be made slowly in order to properly monitor for anaphylactic reactions. More antivenom can then be given as needed, based upon the progression of local tissue signs and/or laboratory tests. 
Most physicians state that antivenom solution should always be given intravenously (Chippaux and Goyffon, 1991; Gomez and Dart, 1995; Russell, 1996), however some recommend administration of 5 to $10 \mathrm{cc}$ of the reconstituted, but not diluted, antivenom around the site of the bite (Package Insert). However, Chippaux and Goyffon (1991) advises against subcutaneous administration of antivenom, as it is painful and weakly effective. Antivenom can be given in the deep muscles of the thigh (Chippaux and Goyffon, 1991; Warrell 1995), but only if venous access is not readily available. Intramuscular infusions, however, are discouraged by Gomez and Dart (1995). Antivenom should not be injected into fingers or toes (Gomez and Dart, 1995). Although there is controversy as to how long after a bite immuno-therapy becomes futile, antivenom should be given as soon as possible. Russell (1996) claims antivenom therapy is of little value for most local and some systemic signs 12 hours post envenomation, but advocates its use 30 hours after envenomation for treating coagulopathy. Wingert (1991) used mouse models to extrapolate this time out to 60 hours. These extended times are in regards to systemic effects. Antivenom has been shown to have very little neutralizing effect of local damage, even when administered immediately following experimental envenomation (Russell, 1973; Rucavado and Lomonte, 1996).

\section{Complications of antivenom therapy}

The ultimate goal of antivenom therapy is to reduce morbidity and mortality resulting from envenomation. However, antivenom therapy has both 
local and systemic consequences. While antivenom is effective at reducing mortality, it is often ineffective at reducing the local morbidity at the site of the bite (Ownby et al., 1983; Lomonte et al., 1993a; Rucavado and Lomonte, 1996). The failure of antivenom to inhibit local tissue reactions is not only a problem associated with time, but also its accessibility to the venom. Not only is the average time to a medical facility in developed countries around 60 minutes (Arnold, 1982), but medical assessment depends on the formation of the local signs in order to determine the proper course. Such evaluations also add time before treatment. Additionally, research has shown that antivenom may not have the capacity to neutralize all of the toxins within venom that are responsible for local tissue damage (Dart and Horowitz, 1996). For example, Ownby and Colberg (1987) showed that Wyeth's Polyvalent (Crotalidae) antivenom contains few antibodies to the toxins of one species of rattlesnake (Crotalus viridis viridis). Ownby et al. (1984) also showed that Wyeth's polyvalent (Crotalidae) antivenom did not effectively neutralize myotoxin $a$, which plays a crucial role in the development of muscle damage following prairie rattlesnake envenomation, when experimentally injected into mice. However, the total time prior to antivenom treatment is typically soon enough to fight severe systemic reaction induced by the venom and therefore eliminate the chances of fatalities (Ownby et al., 1984; Chippaux and Goyffon, 1991). This situation has prompted interest into the development of an appropriate and medically efficacious first-aid therapy. 
Another drawback of antivenom therapy is its potential to induce anaphylactic shock. The nature of the relationship between antivenom and adverse reactions are well documented Gomez and Dart (1995), Warrell (1996) and Chippaux and Goyffon (1991). Since the antivenom is made from horse or sheep serum, the patient's immune system may react immunologically with the foreign antibodies. Signs of anaphylaxis include utricaria, itching, hypotension and respiratory distress. This adverse response to antivenom is primarily caused by diffuse activation of the complement cascade, as opposed to type I hypersensitivity (Warrell, 1995). This acute systemic reaction should not be confused with the systemic reactions that are the result of the damage to vital organs due to venom toxins. Shock is a physiological response to either the presence of foreign proteins or the psychological trauma of having been bitten. Damage to the internal organs such as the heart or kidneys generally takes several hours. It is this damage that antivenom is designed to prevent.

Research has also indicated a common occurrence, possibly as high as 75\% (Gomez and Dart, 1995; Consroe et al., 1995) of serum sickness in patients who receive more than 5 vials of antivenom (Wingert, 1991; Gomez and Dart, 1995). Serum sickness is a delayed serum reaction, or type III hypersensitivity that occurs days to weeks following antivenom therapy. It is caused by conglomerations of antigen-antibody complexes lodged within tissues, especially the kidney. Signs of serum sickness include utricaria, swollen joints, lymphadenopathy, and proteinuria (Wingert, 1991; Gomez and Dart, 1995). The adverse reactions related to initial antivenom infusions can be reduced by 
concomitant administrations of epinephrine and/ or histamine blocking agents, such as diphenhydramine HCL (Wingert, 1991; Gomez and Dart, 1995; Russell, 1996). The appropriate treatment for serum-sickness is corticosteroid therapy (Wingert, 1991).

\section{Controversial treatments of Crotalid envenomation}

While antivenom therapy is the most effective route in treating venomous snakebites, other techniques, such as tourniquets, fasciotomies, cryotherapy, corticosteroids and electro-shock are still controversial. The debates on these alternative snakebite treatment methods are reviewed in Wingert (1991), Gomez and Dart (1995) and Gold (1996). Tourniquets or other constrictive bands are perhaps the most common first-aid techniques applied in the field. It is thought that the constriction of blood flow inhibits the spread of the venom into systemic circulation, but the tourniquet itself could exacerbate local damage. As swelling progresses against the pressure of the band, ischemia increases, as does the venom effects on the already damaged tissues. Animal studies using the Sutherland compression immobilization method showed that an elastic band that constricts only the superficial venous and lymphatic flow, yet permits the flow of arterial supply, retards the spread of the venom without an increase in local damage (Warrell, 1995). However, the inconsistency of band application by the layperson allows this technique to remain controversial and discouraged as an acceptable form of first-aid. 
Fasciotomy is another alternative snakebite treatment that is widely disputed. The technique entails surgically incising tissue fascia in order to relieve increasing pressure caused by continued swelling and has not proved to be effective at treating the local signs of envenomation (Warrell, 1995). Gomez and Dart (1995) and Russell (1996) advocate its use only if arterial supply is clearly impaired or compartmental syndrome is evident. Synder (1991) proposes that a fasciotomy might be the only treatment capable of saving an affected hand or foot. Russell (1996) adds, that despite the presence of profound edema in Crotalid bites, vascular compromise rarely occurs. Sutherland et al. (1979) and Snyder (1991) demonstrated that properly applied ligatures and surgical excision, respectively, could reduce the tissue uptake of venom and overall damage, but these experiments were performed in controlled and/or sterile environments.

Corticosteroids are another popular, and highly debated, treatment for venomous snakebites. There is no clear indication that their use has any therapeutic effect against the venom toxins (Arnold, 1982; Burch et al., 1988) and the administration of steroids in snakebite cases should be reserved for treatment of anaphylactic reactions (Gomez and Dart, 1995; Russell, 1996). Cunnigham et al. (1979) demonstrated that concurrent use of corticosteroids while experimentally injecting Crotalus adamanteus venom dramatically increased lethality.

Cryotherapy is another alternative treatment which can do more harm than good. It was once thought that vasoconstriction due to cold would decrease 
the spread of venom, and that the cold itself would inhibit the venom action. Wingert (1991) describes that freezing already poisoned tissues adds to the overall necrosis and that low temperatures do not diminish the proteolytic action of venom enzymes. The use of cryotherapy is discouraged by most medical professionals.

The practice of electroshock therapy is perhaps the most "one-sided" controversial topic of snakebite treatment. The recent fervor upholding its use occurred when Guderian et al. (1986) reported the success of electrical current to treat snakebite in the Woarani Indians in Ecuador, but the practice of electroshock therapy has been around since the turn of the century (Gold, 1995). Though some believe that electricity shortens the half-life of the venom (Guderian et al., 1986), or alters the hydrogen ion structure of the venom toxins (Kroegel and Meyer zum Buschenfelde, 1986), these actions are not consistent with the chemical or physical properties of the venom (Gold, 1995). Howe (1988) was unable to show adequate reduction in the spread of venom using electroshock therapy in rat models. The current interpretation by most toxinologists is that Guderian treated an "immune" population, as the Woaranis already had high antibody titers due to the increased number of venomous encounters in that region (Wingert, 1991; Gold, 1995). The true efficacy of electroshock therapy has never been proven in controlled studies, and should be discouraged (Gomez and Dart, 1995; Russell, 1996). 


\section{$\underline{\text { Research for effective first-aid therapy }}$}

The goal of an effective first-aid therapy is to rapidly and effectively neutralize those components of snake venom that are primarily responsible for local tissue damage. Specifically, phospholipase $A_{2} S$ are primarily responsible for myotoxicity (Ownby, 1990; Mebs and Ownby, 1990; Lomonte, 1994) and are implicated directly and indirectly in the formation of edema (Lomonte, 1994). Metalloproteinases are responsible for hemorrhage (Bjarnason and Fox, 1988). Administration of a chemical agent that is antagonistic toward one or more of these venom constituents soon after a bite could perhaps reduce the overall brunt of the venom action and therefore decrease the need for extensive therapy at a medical facility. Melo et al. (1994) investigated the ability of certain extracts from the plant, Eclipta prostrata, to neutralize myotoxic and hemorrhagic activity of Crotalid venoms. Melo and Suarez-Kurtz (1988) and Melo et al. (1993) also showed the ability of heparin and other polyanions to inhibit crotalid venom action. Earlier work by Ownby et al. (1975) identified a number of substances, namely procaine $\mathrm{HCl}$ and chelating agents like diethylenetriaminepentaacetic acid (DTPA), as able to antagonize venom components (Ownby and Tu, 1977). Ownby et al. (1997) demonstrated that para-bromophenacyl bromide ( $p$-BPB), a $\mathrm{PLA}_{2}$ inhibitor that acts by binding to the histidine residue in the active site of the enzyme (Volwerk et al., 1974), is an effective antagonist of the myotoxic activity of a PLA myotoxin from Crotalus viridis viridis venom. This $P L A_{2}$-inhibitor also antagonizes a PLA ${ }_{2}$ myotoxin from Agkistrodon contortrix laticinctus venom 
(Melo and Ownby, 1996). Unfortunately, many of these antagonists work only in vitro, not in vivo. That is, the antagonist neutralizes the venom when mixed with the venom prior to injection, but not when it is administered after the injection of venom. The apparent lack of success of these types of compounds has lead to the interest in improving antivenom studies. Lomonte et al. (1987;1990), Rucavado and Lomonte (1996), Gutierrez et al. (1996) have tested various methods for neutralizing crotalid venom with antivenom. Again, the in vitro neutralization capacity of antivenom far surpasses its in vivo capabilities to reduce local tissue damage. As venomous snakebites are rarely fatal, the goal of effective first-aid is to combat and eliminate the local damage.

\section{Components of snake venom}

Snake venom is a complex mixture of enzymatic and non-enzymatic proteins designed to incapacitate and kill the prey animal with toxins that either attack the nervous system, cardiovascular system and/or destroy tissues. It contains enzymes and other proteins, lipids, carbohydrates, amino acids, amines and various free ions that act synergistically to produce the overall venom effects (Tu, 1977; Stocker, 1990). These effects can be seen readily at the level of muscle tissue either by destroying the tissue itself or by affecting nervous 
transmission at the neuro-muscular junction. Table 5 provides an abbreviated list of the components of a crotalid venom. Although venom toxins affect all cell types, toxins are often classified as hemorrhagic, neurotoxic and sometimes myotoxic. As this literature covers only Crotalid venoms of North America, the neurotoxic components of snake venom will not be discussed.

\section{Myotoxic Action of Snake Venom}

Myonecrosis, and other types of local tissue damage, is characteristic of envenomation from snakes of the Crotalidae family (Ownby, 1990; Mebs and Ownby, 1990). Only a few Crotalid venoms are known to contain neurotoxins, such as crotoxin and crotoxin-like toxins (Mebs and Ownby, 1990; Lomonte, 1994). All crotalid venoms examined contain myotoxins. This fact should not be surprising as muscle comprises most of the body's mass and the 
TABLE 5

COMPONENTS OF SOME CROTALID SNAKE VENOMS

\section{Component}

\section{Enzymes}

Phospholipases $\mathrm{A}_{2}$

5-Nucleotidase

Acid phosphatase

Phosphodiesterase

Ribonuclease I

Deoxyribonuclease

Adenosine triphosphatase

NAD-nucleosidase

Hyaluronidase

Heparinase

Proteinases, unspecific

Kininogenases

B-Fibrinogenase, coagulant

Fibrinolytic proteinases

Protein $\mathrm{C}$ activator

Hemorrhagic proteinases

Collagenase

Elastase

Antithrombin III proteinase

Plasma proteinase inhibitors
Component

Nonenzymatic proteins

Neurotoxins

Cytotoxins

Myotoxins, non-PLA ${ }_{2}$

Bradykinin-potentiating peptide

Nerve growth factors

Lectins

Nonprotein components

Lipids

Carbohydrates

Riboflavin

Amino acids, free

Biogenic amines

Catecholamines

Metallic cations

Anions

From Stocker (1990) 
function of snake venom is not only to kill prey, but to begin digestion (Harris and Cullen, 1990; Dufton, 1993). There are several types of toxins that produce myonecrosis: small, nonenzymatic proteins; non-neurotoxic myotoxic phospholipases $\mathrm{A}_{2} \mathrm{~S}$; and hemorrhagic toxins that also produce myotoxicity (Ownby et al., 1978; Tu, 1991; Lomonte, 1994). A fourth type could be added by mentioning the neurotoxic PLA $A_{2}$ that also induce myonecrosis, such as found in the venom of $C$. durissus terrificus. A list of the various types of myotoxins is found in Table 6.

The first group of myotoxins are the small, nonenzymatic proteins. The best known, and most widely studied is myotoxin a, from $C$. viridis viridis (Ownby et al., 1976; Cameron and Tu, 1977). Myotoxin $a$ is composed of 42 amino acid residues and has a molecular weight of about 4000 (Fox et al., 1979). Myotoxin a dilates the sarcoplasmic reticulum leading to muscle cell damage (Mebs and Ownby, 1990). The swelling of the cell is due to a change in ion permeability that eventually leads to the rupture of the plasma membrane, thus inducing cell death. Another toxin of this type is crotamine, from $C$. durissus terrificus. It is also very basic, about the same size as myotoxin $a$, and its action is nearly identical (Laure, 1975).

The second and most ubiquitous type of myotoxins are the PLA $A_{2} \mathrm{~S}$, which catalyze the hydrolysis of 3-sn-phosphoglycerides at the 2-position (Kini and Evans, 1989). These toxins can be of the neurotoxic or non-neurotoxic variety. The non-neurotoxic $\mathrm{PLA}_{2} \mathrm{~S}$ can be further divided into enzymatically and nonenzymatically active proteins (Mebs and Ownby, 1990; Lomonte, 1994). An 
TABLE 6

A CLASSIFICATION OF MUSCLE-DAMAGING TOXINS FROM SNAKE VENOMS

Group

(1) Small myotoxins

(2) Cardiotoxins ${ }^{\star}$

(3) PLA 2 myotoxins

a. neurotoxic complexed

b. non-neurotoxic

b'. enzymatically-active

b". enzymatically-inactive

(4) Indirect myotoxic factors

\section{Characteristics}

Basic, non-enzymatic, single chain peptides of $42-45$ a.a.

Basic, non-enzymatic, single chain proteins of -60 a. a.

Basic, single chain (120 a.a.) or

proteins with $\mathrm{PLA}_{2}$ activity and presynaptic neurotoxicity.

Basic, single chain (-120 a. a.) or dimeric proteins with $\mathrm{PLA}_{2}$ structure.

Asp49 PLA $\mathrm{P}_{2} \mathrm{~S}$

Lys-49 (or other variant) PLA $A_{2}$

May damage skeletal muscle by indirect mechanisms, perhaps through ischemia

Lomonte (1994)

* Not found in Crotalid venoms 
abridged list of some Crotalid $\mathrm{PLA}_{2} \mathrm{~S}$ is provided in Table 7. However, since a number of isoforms have been isolated in this group that were unable to hydrolyze phospholipids due to changes in the amino acid sequence, it is clear that enzymatic activity is not necessary for myotoxic action (Lomonte and Gutierrez, 1989; Johnson and Ownby, 1993a; Lomonte, 1994). Recent cloning and sequencing of the genes coding for these proteins indicated a new class, K49 PLA , which apparently lacks catalytic activity on artificial substrates (Araujo et al., 1996). With the exception of the myotoxin from Vipera ammodytes ammodytes (ammodytoxin L), which contains a serine residue, all of the enzymatically inactive PLA 2 have a lysine residue in position 49 . Those that are enzymatically active have aspartate in that position (Lomonte, 1994). Example of a Lys-49 PLA 2 and Asp-49 PLA 2 are found in the venoms of $A$. contortrix laticinctus (Johnson and Ownby, 1993a) and C. viridis viridis, (Ownby et al., 1997), respectively. It is speculated that the primary site of action of these PLA 2 myotoxins is the plasma membrane of the muscle fiber. However, the precise mechanism of action, as well as the mechanism of the toxin's selectivity for this tissue, remains unclear (Lomonte, 1994; Fletcher et al., 1997).

The third group of myotoxins are the hemorrhagic toxins that also have myotoxic activity (Ownby et al., 1978; Fabiano and Tu, 1981; Queiroz et al, 1985; Harris and Cullen, 1990). In this instance, myonecrosis is usually secondary. As the hemorrhagic toxins break the capillaries and other vessels 


\section{TABLE 7}

TOXIC PHOSPHOLIPASES $A_{2}\left(P L A_{2}\right)$ IN SOME CROTALID VENOMS

\begin{tabular}{lll} 
Name & \multicolumn{1}{c}{ Origin } & Action \\
\hline Myotoxin & Agkistrodon bilineatus & Local Myonecrosis \\
Myotoxin & A. p. piscivorus & Local myonecrosis \\
Myotoxin & A. c. laticinctus & Local myonecrosis \\
Crotoxin & C. durissus terrificus & Pre/post-synaptic neurotoxin \\
Mohave toxin & C. scutulatus & Presynaptic neurotoxin/ \\
Myotoxin & C.v. viridis & muscle cell damage \\
& & Local myonecrosis \\
& & \\
\hline
\end{tabular}

From Stocker (1990) 
supplying muscle tissue, the region becomes ischemic, and the muscle cells begin to die from a lack of oxygen.

The majority of toxins that induce myonecrosis are related to those animal enzymes that function in digestion, and thus have evolved to be particularly rapid and devastating in action. For humans, the onset of myotoxicity can occur so quickly that even the administration of antivenin minutes after envenomation will do little in the prevention of local tissue damage (Reid et al., 1963). This type of damage can lead to loss of fingers, toes and other extremities (Tu, 1991). For small prey animals, the myotoxic components attack the major organs systems as well, leading to death due to internal digestion (Tu and Homma, 1970).

\section{Hemorrhagic Action of Snake Venom}

Another striking feature of local tissue damage is that of hemorrhage, or the rupture of vascular endothelial cells. Hemorrhagic toxins are common to the venoms of Viperidae and Crotalinae, and a venom may contain more than one (Tu, 1991). Hemorrhagic toxins are not specific for those families, however, as Ophiophagus hannah of the Elapids contains a species specific toxin (Weissenberg et al., 1987). Hemorrhagic toxins are all, to some degree, proteases (zinc metalloproteinases) ranging from $25 \mathrm{kDa}$ to $90 \mathrm{kDa}$ in molecular weight. The larger hemorrhagic proteins generally tend to be more active in vivo (Bjarnason and Fox, 1988) due to the presence of a disintegrin domain (Hite et al., 1992). Disintegrins are low-molecular weight peptides that can inhibit platelet 
aggregation. It is known that the basal lamina of capillaries is often disrupted by hemorrhagic toxins (Ownby et al., 1978), and it is hypothesized that the disintegrin domain targets the integrins of the vascular endothelia (Takeya et al., 1990).

The effects of hemorrhagic toxins occur much faster than those of myotoxins ( $\mathrm{Tu}, 1991)$, but the details of their mechanism of action are still incomplete. One theory indicates that small breaks in the basal lamina induced by the toxins stimulates an endogenous action that then rapidly degrades the endothelium (Lomonte, 1994). By whatever process the vessel breaks, there are two methods in which the erythrocytes escape. Interestingly, these processes may be toxin specific, too. Hemorrhage per diapedesis occurs when red blood cells exit the vessel through enlarged intercellular junctions of the endothelial cells (Ownby, 1990). A toxin isolated from the venom of Trimeresurus flavoviridis was shown to induce hemorrhage of this type (Oshaka et al., 1975). Hemorrhage per rhexis occurs as erthyrocytes escape the vessel through true transcellular gaps within a damaged endothelial cell (Ownby, 1990). Several toxins purified from the venoms of a number of Crotalids caused red blood cell extravasation per rhexis (Ownby et al., 1978; Ownby, 1990). 


\section{Other Components of Snake Venom}

In addition to the potent neurotoxins, myotoxins and hemorrhagic toxins, snake venoms also contain a number of relatively non-toxic components. About $90 \%$ of snake venom components are proteins, but only a relatively small number of these are the active toxins. Hyaluronidase, of course, and serotonin are present. These are responsible for "spreading" and pain, respectively. Rattlesnake venom also contains a bradykinin-releasing factor that is not common to Hydrophiidae or Elapidae. Small amounts of free amino acids and glycoproteins are typically common to all species. All of these "non-toxic" components are typically synergistic, in that they help increase a venom's overall toxicity. This is particularly true of rattlesnake venom, in which the whole venom is more toxic than the individual toxins alone (Tu, 1982).

$\underline{\text { Venoms of Agkistrodon contortrix laticinctus and Crotalus viridis viridis }}$

The venoms of Agkistrodon contortrix laticinctus (ACL) and Crotalus viridis viridis (CVV) were chosen for this experiment not only for their availability but as representative examples of Crotalid venom. The venom of both species induce the types of local tissue damage investigated in this study, i.e., edema. hemorrhage and myonecrosis. Additionally, apart from the fact that they represent two different genera, it is suggested that the two venoms have slightly different characteristic hemorrhagic and myotoxic actions. 
Myotoxicity induced by Crotalus viridis viridis (CVV) and Agkistrodon contortrix laticinctus (ACL) venoms is in part a result of phospholipase- $A_{2}$ myotoxins (Johnson and Ownby, 1993a; Ownby et al., 1997). The specific myotoxic protein from CVV venom (D49-PLA 2 ) is basic, approximately $14 \mathrm{kDa}$, and has high catalytic activity on artificial substrates (Ownby et al., 1997). The myotoxic molecule of $A C L$ venom (K49-PLA $)$, while having the $P L A_{2}$ structure (Araujo et al., 1996), has little or no enzymatic activity due to a substitution of lysine for aspartic acid at position 49 (Johnson and Ownby, 1993a; Araujo et al., 1996). Both of these PLA2 toxins induce a rapid myonecrosis which is identical to that seen with the crude venoms (Mebs and Ownby, 1990; Fletcher et al., 1997).

Hemorrhage induced by Agkistrodon contortrix laticinctus (ACL) and Crotalus viridis viridis (CVV) venoms is in part a result of metal-dependent metalloproteinases. These enzymes, mostly zinc-dependent, show activity towards substrates such as casein and collagen and range in size from 22,000 $\mathrm{Da}$ to $100,000 \mathrm{Da}$ (Bjarnason and Fox, 1988). Johnson and Ownby (1993b) isolated a hemorrhagic toxin, $A C L$ hemorrhagic toxin $\mathrm{I}$, from the venom of the Broad-banded Copperhead that has a molecular weight of about $29,000 \mathrm{Da}$. It is similar in behavior to other hemorrhagic toxins found in other venoms, as it shows enzymatic activity towards protease substrate and can be inhibited by EDTA, suggesting that it is a metalloproteinase. Li et al. (1993) isolated two high-molecular weight hemorrhagic toxins from the venom of $C$. viridis viridis, both of which are metalloproteinases and are proteolytic on such substrates as 
$\mathrm{N}, \mathrm{N}$-dimethylcasein and fibrinogen. One of the toxins has a molecular weight of $68,000(p /$ of 8.5$)$ and the other toxin has a weight of $62,000(p /$ of 4.1). Based of behavior and molecular weights, the two toxins are reported to be similar to another hemorrhagic toxin in CVV venom, viriditoxin (Gleason et al., 1983). Viriditoxin, a high-molecular weight hemorrhagic toxin, first reported by Fabiano and Tu (1981), consists of two protein subunits of molecular weights of 57,000 and 62,000 . These two toxins differ from ACL hemorrhagic toxin I in that they both digest the $A \alpha$-chain of fibrinogen without hydrolyzing the $B \beta$ chain, while the ACL toxin digests both fibrinogen chains. The two CVV toxins differ from each other in that the $62,000 \mathrm{~mol}$. wt. toxin lost its activity when its sugar moiety was oxidized, but the 68,000 wt. toxin retained hemorrhagic ability (Li et al., 1993).

The edema-forming activity of ACL and CVV is not well documented and is a major purpose of the proposed research. However, since PLA $\mathrm{A}_{2}$ toxins from Bothrops asper (Lomonte and Gutierrez, 1989), Trimeresurus mucrosquamatous (Liu et al., 1991) and Bothrops schlegelii (Angulo et al., 1997) venoms have been reported to induce edema, it is likely that both the ACL and CVV myotoxins contribute to the edema induced by the $\mathrm{ACL}$ and $\mathrm{CVV}$ crude venoms, respectively. 


\section{CHAPTER 2.}

\section{ABSTRACT AND INTRODUCTION}

\section{Abstract}

Venoms of the Broad-banded Copperhead (Agkistrodon contortrix laticinctus) and the Prairie Rattlesnake (Crotalus viridis viridis), like other Crotalid venoms, cause severe local tissue damage such as edema, hemorrhage and myonecrosis (Ownby, 1990). Antivenom (Ax), though generally effective at reducing systemic signs related to mortality, is rather ineffective at reducing morbidity unless incubated with the venom prior to injection (Russell, 1973) and has been shown to be ineffective in neutralization of the effects of CVV venom (Ownby and Colberg, 1987). Such observations support the need for an effective first-aid regimen aimed at minimizing local tissue reactions. Some of the myotoxic activity of these venoms is due to phospholipase $A_{2}$ toxins, such as ACL myotoxin (Johnson and Ownby, 1993a) and CVV myotoxin (Ownby et al., 1997). Since para-bromophenacyl bromide, an inhibitor of the PLA $A_{2}$ catalytic activity, has been shown to inhibit the myotoxic action of these two PLA 2 myotoxins, we hypothesized that this compound would inhibit part of the myotoxic activity of these crude venoms. Initially, the venoms were mixed with either $p$-BPB or Ax prior to injection. Later, the venoms were mixed with both $p$ - 
BPB and Ax prior to injection into the muscles of the lower hindlimb of mice. These tests were performed to measure the in vitro neutralization capacity of the antagonists for $\mathrm{ACL}$ and $\mathrm{CVV}$ venoms. In tests to determine the in vivo neutralization ability of the antagonists, mice were injected with venom followed by either topical DMSO containing p-BPB or injected i.m. with saline containing $p$-BPB. A final set of mice received the in vivo treatment as described above, but were followed by i.p. infusions of $A x$ in order to simulate experimental first-aid, then hospital treatment. Edema was measured by determining the increase in diameter of the injected leg; hemorrhage by determining the increase of hemoglobin in the muscle sample; and myonecrosis by measuring the rise in creatine kinase levels in the blood. In the in vitro neutralization tests, edema was significantly reduced when both antagonists were used together, but not with either alone. $p$-BPB and Ax tended to increase the hemorrhagic activity of the $A C L$ venom, but halved the CVV induced hemorrhage. The antagonists showed a highly significant neutralization of ACL- and CVV-generated myonecrosis when used individually, and the neutralization was even greater when they were used together. In the in vivo neutralization experiments, i.p. antivenom significantly reduced edema, hemorrhage and myonecrosis induced by CVV venom. Other antagonists induced few statistically significant changes in the parameters measured. However, hemorrhage was significantly reduced when ACL venom was followed by topical DMSO-p-BPB. In general, edema tended to increase with the application of both topical p-BPB in DMSO and i.m. saline containing $p$ BPB. Antivenom reduced the myotoxic effect of both venoms, but the other 
antagonists had no effect in vivo, except when ACL venom was followed by i.m. saline-p-BPB $(p<0.1)$.

Introduction

Venoms of the Broad-banded Copperhead (Agkistrodon contortrix laticinctis) and the Prairie Rattlesnake (Crotalus viridis viridis) can cause severe local tissue damage such as edema, hemorrhage and myonecrosis (Ownby, 1982; Ownby and Colberg, 1987, 1988; Johnson and Ownby, 1993a,b). Antivenom (Ax), though generally effective at reducing systemic signs related to mortality, is rather ineffective at reducing morbidity unless incubated with the venom prior to injection (Russell, 1973) and has been shown to be ineffective in neutralization of the effects of CVV venom (Ownby and Colberg, 1987). Antivenom has not been shown to be very effective at reducing the local tissue damage induced by venom, even when administered immediately after envenomation (Ownby et al., 1983; Lomonte et al., 1993a; Rucavado and Lomonte, 1996). Such observations support the need for an effective first-aid regimen aimed at minimizing local tissue reactions. Some of the myotoxic activity of these venoms is due to phospholipase $A_{2}$ toxins, such as $A C L$ myotoxin (Johnson and Ownby, 1993a) and CVV myotoxin (Ownby et al., 1997). Since para-bromophenacyl bromide, an inhibitor of the PLA $A_{2}$ catalytic activity, has been shown to inhibit the myotoxic action of these two PLA myotoxins, we 
hypothesized that this compound would inhibit part of the myotoxic activity of these crude venoms.

Phospholipase $A_{2}$ toxins are responsible for much of Crotalid venom's myotoxicity (Ownby, 1990; Mebs and Ownby, 1990; Lomonte, 1994), and they are implicated directly and indirectly in the formation of edema (Lomonte, 1994). Administration of a chemical agent that is antagonistic to venom phospholipase $\mathrm{A}_{2}$ could reduce the overall brunt of the venom action, and therefore decrease the need for extensive therapy at a medical facility. Earlier work by Ownby et al. (1975) identified a number of substances, namely procaine HCL and chelating agents like ethylenediaminetetracetic acid (EDTA) and diethylenetriaminepentacetic acid (DTPA), which antagonized the hemorrhagic activity of Crotalus atrox venom. Myotoxicity induced by Crotalus viridis viridis (CVV) and Agkistrodon contortrix laticinctus (ACL) venoms is in part a result of phospholipase- $A_{2}$ myotoxins. The specific myotoxin from CVV venom, CVV myotoxin (D49-PLA 2 ), is basic, about $14 \mathrm{kDa}$ and catalytically active (Ownby et al., 1997). The myotoxic molecule of $A C L$ venom (K49-PLA $A_{2}$, while having the $\mathrm{PLA}_{2}$ structure (Araujo et al., 1996), has little or no enzymatic activity due to a substitution of lysine for aspartic acid at position 49 (Johnson and Ownby, 1993a; Araujo et al., 1996). Ownby et al. (1997) demonstrated that parabromophenacyl bromide, a PLA 2 inhibitor that acts by binding to the histidine residue in the active site of the enzyme (Volwerk et al., 1974), is an effective antagonist of the myotoxic activity of the myotoxin from Crotalus viridis viridis. $p$ BPB also antagonizes the myotoxic activity of ACL myotoxin from Agkistrodon 
contortrix laticinctus in vitro, despite the apparent lack of enzymatic activity (Melo and Ownby, 1996). In addition to hemorrhage and myonecrosis, edema is a prominent local effect of many venoms (Ownby, 1990). While the exact methods of the edema-forming activities are still under investigation, Liu et al. (1991) and Lomonte and Gutierrez (1989) characterized one PLA $\mathrm{P}_{2}$ of $A$. p. piscivorus and Bothrops asper, respectively, specifically as "edema inducing." The PLA 2 enzymes in the venom can also induce damage to the vascular endothelia resulting in hemorrhage (Lomonte et al., 1993b). It is uncertain, however, how much of a contribution each of the crude venom components plays in the formation of local tissue damage.

The purpose of this work was to analyze the ability of $p$-BPB in combination with antivenom to neutralize the local tissue effects of edema, hemorrhage and myonecrosis induced by $\mathrm{ACL}$ and CVV venoms. Since the $\mathrm{PLA}_{2}$ myotoxins are responsible for the myotoxic and edema-forming activities of the $A C L$ and CVV crude venoms, and these activities are inhibited by $p-B P B$, it was hypothesized that the administration of $p$-BPB following injection of $\mathrm{ACL}$ and CVV crude venoms would inhibit the formation of edema and myonecrosis. 


\section{CHAPTER 3}

\section{MATERIALS AND METHODS}

\section{Source of $A$. C. laticinctus and C. v. viridis venoms}

Agkistrodon contortrix laticinctus venom was a pool of venom (Lot \#051793) obtained from 15 snakes collected in central Texas, U.S.A., and maintained at the Venom Research Laboratory Serpentarium, Oklahoma State University, Stillwater, OK, U.S.A. Crotalus viridis viridis venom was a pool of venom (Lot \#091592) obtained from 13 snakes collected from western Oklahoma, positively identified as Crotalus viridis viridis using taxonomic criteria, and maintained in the Venom Research Laboratory Serpentarium, Oklahoma State University, Stillwater, OK, U.S.A. The venom was extracted by allowing the snakes to bite through Parafilm $®$ which covered a glass funnel that emptied into a polycarbonate centrifuge tube resting in an ice bath. Immediately after extraction the venom was centrifuged at $28,000 \times \mathbf{g}$ for $20 \mathrm{~min}$ using a Sorvall RCR5 refrigerated centrifuge $\left(4^{\circ} \mathrm{C}\right)$ to remove insoluble material, frozen, and then lyophilized. Lyophilized venom was stored over desiccant a $-20^{\circ} \mathrm{C}$ until needed. Venom was reconstituted using physiologic saline $(0.90 \% \mathrm{NaCl})$. 
$\underline{\text { Mice }}$

Adult female CD-1 mice (28-30g) were purchased from Charles River Laboratories, Inc., Wilmington, MA.

\section{Inhibitors/Venom Solutions}

The p-BPB was purchased from Sigma Chemical Co., St. Louis, Mo., U.S.A. and was used by adding $1 \mathrm{mg}$ to $1 \mathrm{ml}$ of the appropriate venom or vehicle solution (PSS or DMSO gel) according to Ownby et al. (1997). Antivenom was obtained from Wyeth-Ayerst Laboratories, Mariette, PA, USA. Dimethyl sulfoxide (DMSO) gel and physiologic saline (PSS) gel were purchased from FWI, Tulsa, OK, U.S.A. and Baxter Health Care Corporation, Deerfield, IN, U.S.A., respectively. The DMSO gel was used as a vehicle for transcutaneous absorption of the $p$-BPB for methods described later. In the in vitro tests, venom was reconstituted in either physiologic saline $(0.90 \% \mathrm{NaCl})$ or Wyeth's Polyvalent (Crotalidae) antivenom to form the experimental dose concentrations of venom $(2.0 \mu \mathrm{g} / \mathrm{g}$ for $\mathrm{ACL}$ and $1.0 \mu \mathrm{g} / \mathrm{g}$ for $\mathrm{CVV})$. The antivenom-venom solution was incubated overnight at $4^{\circ} \mathrm{C}$. $\quad$-BPB was added to both the venom and antivenom:venom solutions to a final concentration of $1 \mathrm{mg} / \mathrm{ml}$ for the $p$-BPB and incubated overnight at $37^{\circ} \mathrm{C}$. In the in vivo tests, $p$-BPB was mixed in either PSS or DMSO to a final concentration of $1 \mathrm{mg} / \mathrm{ml}$. Each particular inhibitor solution, minus the crude venom, was used as a control for each particular inhibitor/venom test. The application of venom or antagonist solution is described below. 


\section{Determination of ED50 dose for Edema, Hemorrhage, Myonecrosis.}

To determine the final experimental doses of venom, mice were injected with logarithmic increments of $\operatorname{ACL}(0.1,1.0$, and $10.0 \mu \mathrm{g} / \mathrm{g})$ and $\operatorname{CVV}(0.05,0.5$, and $5.0 \mu \mathrm{g} / \mathrm{g}$ ) venom concentrations. Assays measuring the edema, hemorrhage and myonecrosis (described later) were performed and the dose approximating the ED50 for each parameter was determined. The criteria used for selecting the dose of venom were: (1) at least one $\mathrm{ED}_{50}$, (2) dose which induces measurable local tissue damage, and (3) sub-lethal dose.

\section{Injection Protocol}

In vitro neutralization. The venom and antagonist were incubated together overnight at $37^{\circ} \mathrm{C}$. Each mouse was anesthetized with Methoxyflurane, then the right hindlimb of each mouse was shaved. While under anesthesia, 0.05 $\mathrm{ml}$ of the test solution was injected into the dorsolateral aspect of the right gastrocnemius muscle. At four hours after the injection, each mouse was again anesthetized and euthanized by cervical dislocation. Then, final measurements for edema, and blood and muscle samples were taken.

In vivo neutralization. Mice were treated as in the in vitro protocol except that the venom and antagonist were applied separately. The in vivo treatments were as follows: (A) 1 minute after injection of the venom solution, $0.05 \mathrm{ml}$ of $90 \%$ DMSO gel with or without $p$-BPB $(1 \mathrm{mg} / \mathrm{ml})$ was rubbed onto the site of injection; (B) 1 minute after injection of the venom solution, $0.05 \mathrm{ml}$ of PSS with 
or without $p$-BPB $(1 \mathrm{mg} / \mathrm{ml})$ was injected into the site of injection. Attempts were made to use the same hole made by the initial injection of venom to minimize muscle trauma; $(\mathrm{C})$ protocols $\mathrm{A}$ and $\mathrm{B}$ were repeated as previously described, but thirty minutes after the injection of venom and the experimental treatment, $0.25 \mathrm{ml}$ of antivenom was administered i.p. All samples were taken four hours after injection.

\section{Determination of PLA 2 Activity}

Phospholipase $A_{2}$ activity of venom was determined by measuring the release of free fatty acid from a solution of L-1-phosphatidylcholine resulting in a lessening of coloration as shown by the $\mathrm{pH}$ indicating dye, cresol red, at $578 \mathrm{~nm}$. All reagents for this assay were purchased from Sigma Chemical Co. (St. Louis, Mo., USA). Four solutions were required for the assay: (1) L-1phosphatidylcholine solution, made by dissolving 1 gram of phosphatidylcholine with $10 \mathrm{ml}$ Methanol and $3 \mathrm{ml}$ Triton $\mathrm{X}-100$ and bringing to $20 \mathrm{ml}$ with $\mathrm{dH}_{2} \mathrm{O}$; (2) Indicator solution, made by combining $1.5 \mathrm{mg}$ cresol red and $250 \mu$ l Methanol and bringing to $25 \mathrm{ml}$ with $\mathrm{dH}_{2} \mathrm{O}$; (3) Glycylglycine solution $(0.10 \mathrm{M})$, made by combining $330 \mathrm{mg}$ glycylglycine with $25 \mathrm{ml} \mathrm{dH}_{2} \mathrm{O}$; and (4) Calcium chloride solution $(90 \mathrm{mM})$, made by combining $200 \mathrm{mg}$ calcium chloride with $20 \mathrm{ml} \mathrm{dH}_{2} \mathrm{O}$. The buffered substrate solution (BSS) was made by combining $4 \mathrm{ml}$ of (1), $7 \mathrm{ml}$ of (2), $3 \mathrm{ml}$ of (3), $1 \mathrm{ml}$ of (4) and $10 \mathrm{ml}$ of $\mathrm{dH}_{2} \mathrm{O}$. The $\mathrm{pH}$ of the solution was adjusted to 9.5 , the volume adjusted to $30 \mathrm{ml}$ with $\mathrm{dH}_{2} \mathrm{O}$, and the solution was used immediately. 
Test samples of the various venom and venom:antagonist solutions were prepared as described above in Inhibitors. A $1 \mathrm{ml}$ semi-micro quartz cuvette was put into a Beckman DU-8 spectrophotometer (Beckman Instruments, Inc., Fullerton, CA) and the absorbance was zeroed at $578 \mathrm{~nm}$, then one $\mathrm{ml}$ of BSS was put into the cuvette, and the absorbance was recorded. With one hand, 10ul of sample was put into the cuvette containing BSS, and the solution was immediately mixed with a Pasteur pipette held in the other hand. Absorbance was recorded at one minute after the addition of the sample. The extinction coefficient (e) was determined by recording the Abs 578 of the Buffered saline solution (BSS) and again recording the Abs 578 one minute after adding $10 \mu \mathrm{l}$ of $0.1 \mathrm{~N} \mathrm{HCL}$. The Volume Activity $(\mathrm{U} / \mathrm{ml})$ of venom fractions was determined using the formula $\left(1.01^{\star} \mathrm{E} / 0.01^{\star} \mathrm{e}\right)$ where $\mathrm{E}$ is the change in Absorbance per minute and $\mathrm{e}$ is the extinction coefficient. The Specific Activity was determined by dividing the Volume Activity $(\mathrm{U} / \mathrm{ml})$ by the sample concentration.

\section{Determination of Edema}

With mice under anesthesia, the pre-injection diameter of the lower hindlimb was measured using low-pressure spring calipers. Four hours after the injection, the mouse was euthanized by cervical dislocation and the increase in muscle thickness was measured. Edema was expressed as the percent (\%) increase in diameter of the injected hindlimb. 


\section{Determination of Hemorrhage}

The hemorrhage assay was performed as described in Ownby et al. (1984), with a few modifications. After the allotted four hour time period, the test mice were euthanized by cervical dislocation. The skin was removed from the site of injection (right hindlimb), and the injected muscle was removed. Each muscle sample was weighed, placed in a test tube, and stored overnight at $-20^{\circ}$ C until used. For the assay, samples were removed from the freezer and homogenized in $3 \mathrm{ml}$ of distilled water for 30 seconds using a Brinkmann Polytron PT (Brinkmann Instruments, Westbury, NY) at a setting of 5 . The homogenates were then centrifuged in an Eppendorf centrifuge for 10 minutes at $5000 \mathrm{rpm}$. The supernatant between the precipitate on the bottom and foam-like layer on the top was removed and centrifuged in a Sorvall RC2B refrigerated centrifuge at $18,500 \mathrm{rpm}$ for 45 minutes. Centrifugation of less than 30 minutes was not sufficient to clear the supernatant. This supernatant was carefully removed so as not to disturb the overlying lipid layer and returned to the Sorvall centrifuge at $18,500 \mathrm{rev} / \mathrm{min}$ for another twenty minutes. Then, $1800 \mu \mathrm{l}$ of the final supernatant was again carefully removed. The amount of hemoglobin in the supernatant was measured by the cyanomethemoglobin method, as described in Sigma Technical Bulletin No. 525, with the following modifications. Drabkins reagent was mixed at twice normal strength ( 1 vial $+500 \mathrm{ml} \mathrm{dH_{2 }}$ ), as described in Ownby et al. (1984), and standards were mixed using the twice normal strength Drabkins, and $1800 \mu \mathrm{l}$ of supernatant from homogenized muscle was added to $5 \mathrm{ml}$ Drabkins reagent. Then, $20 \mu \mathrm{l}$ aliquots were placed in a 96 well 
plate and the absorbance at 520nm was determined using a THERMOmax ${ }^{\mathrm{TM}}$ microplate reader (Molecular Devices), and the grams per $100 \mathrm{ml}(\mathrm{g} \%)$ of hemoglobin was obtained from a standard curve. A standard curve was obtained each time using lyophilized human methemoglobin. The $g \%$ hemoglobin was corrected for weight of muscle sample by dividing by the weight of the muscle.

\section{Determination of Myonecrosis}

Myonecrosis was evaluated by quantification of serum creatine kinase (CK) using a Sigma Creatine Phosphokinase assay (Sigma No. 520). Four hours after an i.m. injection (in the right gastrocnemius) while under anesthesia, blood was collected into non-heparinized capillary tubes from the infraorbital plexus and immediately spun in a hematocrit centrifuge to separate the serum and erythrocytes. For the assay, $10 \mu \mathrm{l}$ of serum was added to $0.5 \mathrm{ml}$ phosphocreatine solution in a $10 \mathrm{ml}$ glass test tube and placed in a water bath at $37^{\circ} \mathrm{C}$. Then, $0.2 \mathrm{ml}$ of ADP-Glutathione were immediately added to the serum solution and allowed to incubate for exactly 30 minutes. After 30 minutes, $0.2 \mathrm{ml}$ p-hydroxymercurobenzoate was added to stop the reaction. The test tube was removed from the water bath and $1 \mathrm{ml} \alpha$-napthol solution, $1 \mathrm{ml}$ diacetyl solution and $7 \mathrm{ml} \mathrm{dH_{2 }} \mathrm{O}$ were added. The tube was returned to the water bath for another 15 minutes. Separate solutions for a standard curve were made by adding 0 , $0.2,0.4,0.6,0.8$ and $1 \mathrm{ml}$ of creatine standard solution (Sigma No. 520-C) to the $\alpha$-napthol, diacetyl and $\mathrm{dH} 2 \mathrm{O}$ solution. Next, $0.2 \mathrm{ml}$ of the standard and test 
solutions were transferred to a 96 well ELISA plate and the absorbance read at $520 \mathrm{~nm}$. Serum $[\mathrm{CK}]$ was determined from the standard curve. Results were expressed as Sigma Units/ml. 


\section{CHAPTER 4}

\section{RESULTS}

Determination of $\mathrm{ED}_{50}$ venom dose for Edema, Hemorrhage and Myonecrosis.

The $\mathrm{ED}_{50}$ values for each of the local tissue damage parameters generally occurred within the same range for the respective venoms. Figures 1 and 2 show the results of the dose/response experiments for both venoms for edema, hemorrhage and myonecrosis. Final experimental doses of $2.0 \mu \mathrm{g} / \mathrm{g}$ for $\mathrm{ACL}$ and $1.0 \mu \mathrm{g} / \mathrm{g}$ for CVV were chosen as these values approximated an $\mathrm{ED}_{50}$ for each of the experimental assays, were less than the $\mathrm{LD}_{50}$ and induced measurable edema, hemorrhage and myonecrosis.

\section{$\underline{\text { In vitro neutralization }}$}

When mice were injected with either $A C L$ or $C V V$ venom that was incubated with the antagonists, overall local tissue damage was significantly reduced $(p<0.05)$ when compared to the venom alone using the Student's ttest. Venom solutions that were incubated with both $p$-BPB and antivenom showed greater reduction of edema, hemorrhage and myonecrosis than solutions that contained only one antagonist. Figure 3 shows that edema induced by either venom was only slightly inhibited when the antagonists were used separately, but edema induced by $A C L$ venom and CVV venom was 
reduced by about 85 and 90 percent, respectively, when the antagonists were used in combination. Edema induced by CVV venom was also significantly reduced when combined in vitro with only antivenom. Figure 4 demonstrates that hemorrhage induced by $A C L$ or CVV venom was reduced by about 50 percent regardless of the antagonist combination. Figure 5 shows that both $p$ BPB and antivenom reduced myonecrosis induced by both venoms when used alone, but neutralized the myotoxicity induced by the $A C L$ and $C V V$ venoms by 85 to $90 \%$ when used in combination. Also, $p$-BPB was more effective than antivenom in reducing myonecrosis induced by $\mathrm{ACL}$ venom, but antivenom was more effective for CVV venom.

\section{$\underline{\text { In vivo neutralization }}$}

\section{Topical}

In general, mice that were injected with either ACL or CVV venom, and then treated topically with either DMSO gel alone or DMSO gel containing parabromophenacyl bromide, showed no reduction of local tissue damage. In fact, Figure 6 shows a significant increase in edema in mice treated with DMSO or DMSO-p-BPB following injection of $\mathrm{ACL}$ venom and DMSO-p-BPB following injection of CVV venom. Figure 7 shows that in most cases there was no significant change in hemorrhagic activity for the treated mice compared to venom alone, except for a single significant reduction of hemorrhagic activity when mice injected with $\mathrm{ACL}$ venom were treated with DMSO containing $p$-BPB. 
Figure 8 shows that there was no significant change in myonecrosis between the mice injected with either venom alone, and those that recieved any antagonist alone or in combination.

\section{Intramuscular}

In general, mice that were injected with either $\mathrm{ACL}$ or CVV venom, and then injected with either saline or saline containing $p$-BPB, showed no appreciable change in local tissue damage when compared to venom alone. Figure 9 shows that a significant increase in edema occurred when an injection of $\mathrm{ACL}$ venom was followed by an injection of saline. Figure 10 shows that the only significant change was an increase in hemorrhagic activity when an injection of $\mathrm{ACL}$ venom was followed by an injection of saline containing $p$-BPB. Figure 11 records that no significant change in myonecrosis occurred between groups receiving either venom alone or venom followed by i.m. saline or saline with $p$ BPB at a significance level of $p<0.05$. Myonecrosis induced by $A C L$ venom after i.m. saline-p-BPB was reduced, but at a significance level of $p<0.1$.

\section{Antivenom}

Both the topical and i.m. treatments followed by i.p. injections of antivenom 30 minutes after venom showed few significant reductions of local tissue damage parameters. In fact, most significant changes were positive. Figure 12 shows a significant increase in edema with all treatments following injection of $A C L$ venom when compared to the value for venom alone or venom 
followed by antivenom. Mice receiving antivenom alone and mice receiving saline- $p$-BPB following injections of CVV venom demonstrated a significant reduction in edema when compared to CVV venom alone.

Figure 13 shows that the only significant reduction in hemorrhage was obtained for CVV venom followed by antivenom alone or by i.m. saline- $p$-BPB and antivenom. All other significant changes were increases.

Figure 14 shows a significant decrease in myonecrosis in mice receiving antivenom, DMSO- $p$-BPB and saline- $p$-BPB treatments following injections of CVV venom alone. ACL- induced myonecrosis was also reduced by i.p. antivenom compared to venom alone, but only at a significance level of $p<0.1$. Figure 14 also demonstrates that there was no significant changes in myotoxicity when venoms were followed by topical treatment, then antivenom, when compared to antivenom treatment alone. 


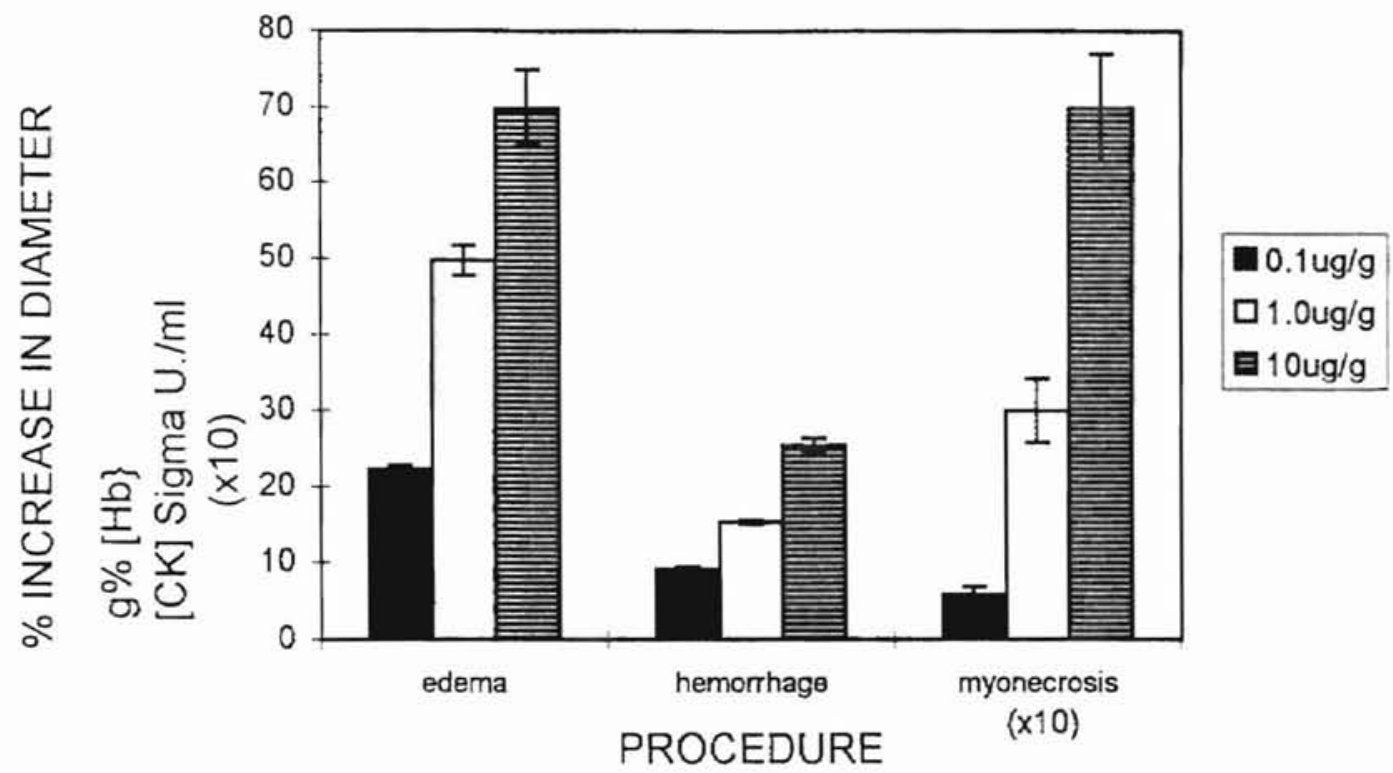

Figure 1. Dose-response relation of local tissue damage parameters following injection of $\mathrm{ACL}$ venom at $0.1,1.0$ and $10.0 \mu \mathrm{g} / \mathrm{g}$. Edema is measured in \% increase in diameter; Hemorrhage is measured in $\mathrm{g} \%[\mathrm{Hb}]$ for muscle samples; Myonecrosis is measured in Sigma units/ml for CK. 


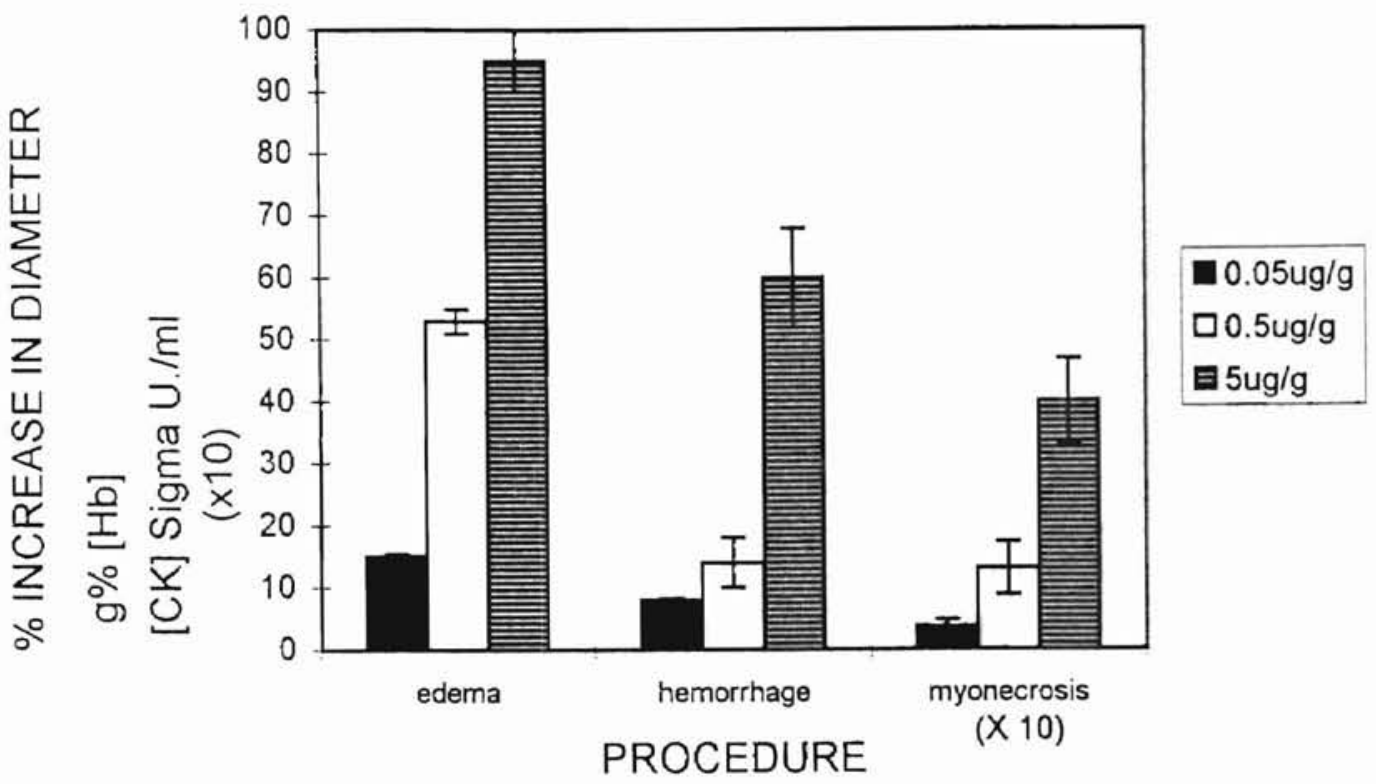

Figure 2. Dose-response relation of local tissue damage parameters following injections of CVV venom at $0.05,0.5$, and $5.0 \mu \mathrm{g} / \mathrm{g}$. Edema is measured in \% increase in diameter; Hemorrhage is measured in $\mathrm{g} \%[\mathrm{Hb}]$ for muscle samples; Myonecrosis is measured in Sigma units/ml for CK. 


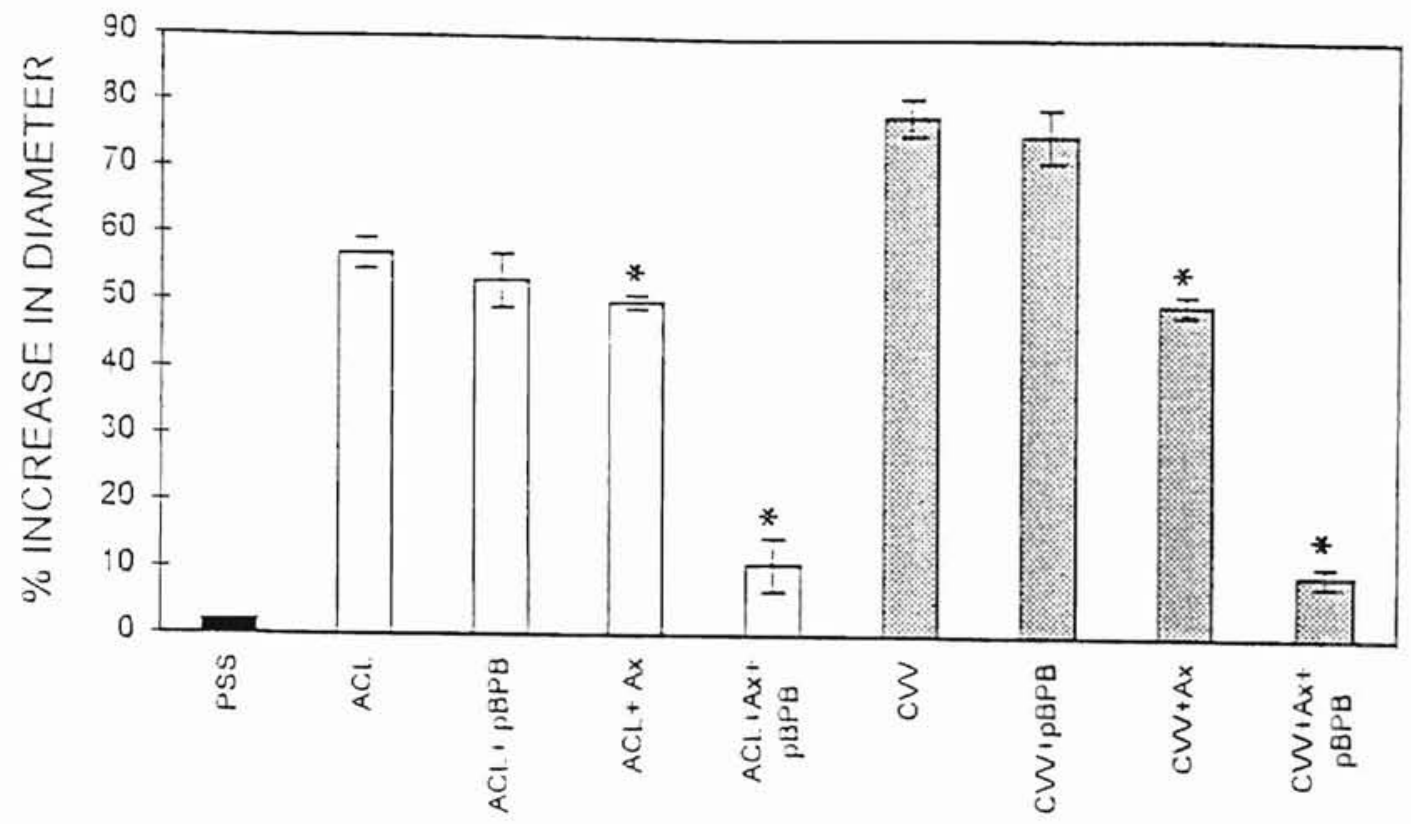

TREATMENT

Figure 3: In vitro neutralization of edema induced by $\mathrm{ACL}$ and $\mathrm{CVV}$ venoms. $\mathrm{PSS}=0.90 \% \mathrm{NaCl} ; \mathrm{ACL}=A$. contortrix laticinctus venom $(2.0 \mu \mathrm{g} / \mathrm{g}) ;$ CVV $=$ C. viridis viridis venom $(1.0 \mu \mathrm{g} / \mathrm{g}) ; \mathrm{pBPB}=$ parabromophenacyl bromide; $A x=$ Wyeth's Polyvalent (Crotalidae) Antivenin . Bars represent mean $=$ S.E.M. $(n=4) . \quad$ * Indicates damage level significantly different at $p<0.05$ when compared to venom alone using Student's t-test. 


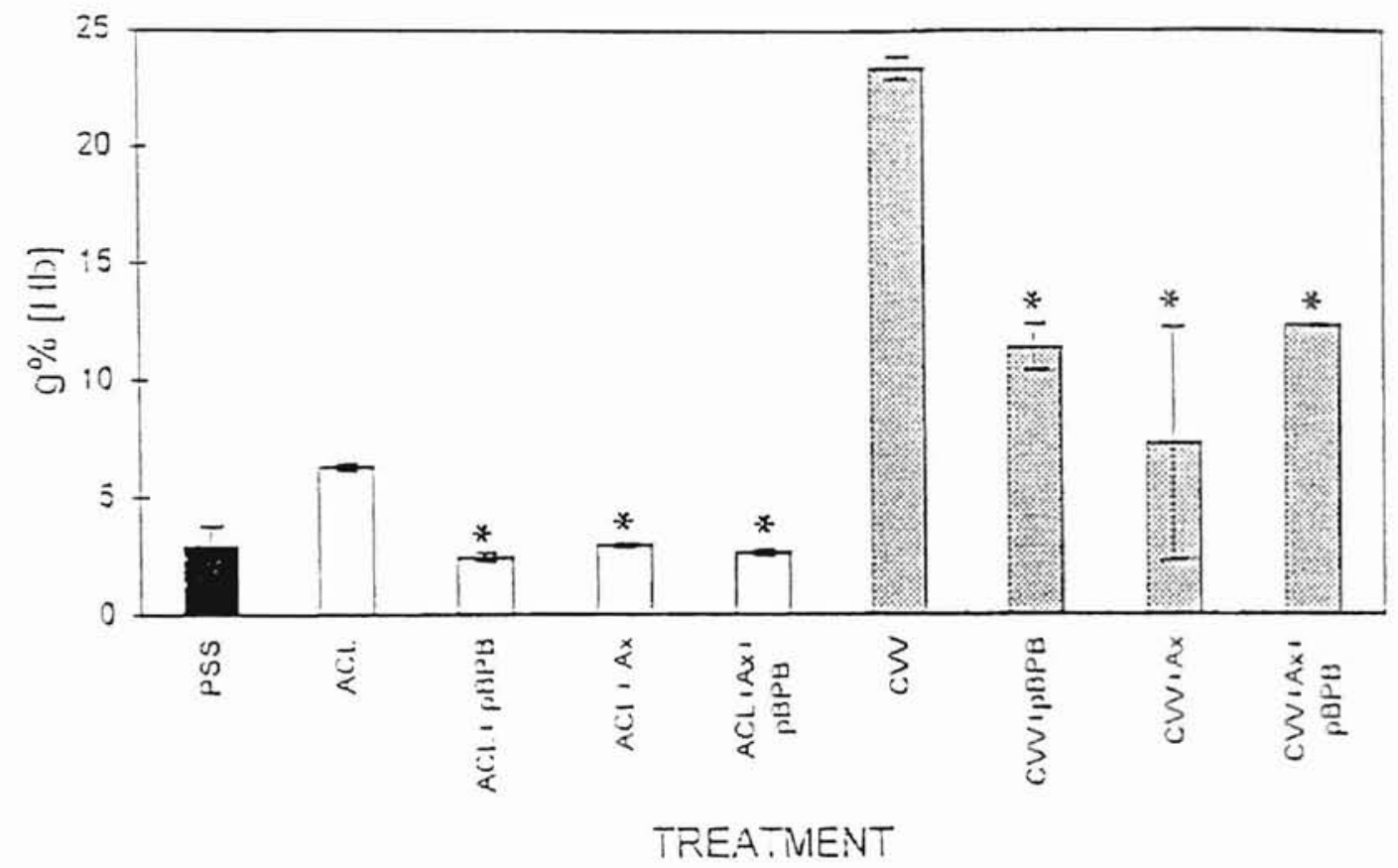

Figure 4: In vitro neutralization of hemorrhage induced by $\mathrm{ACL}$ and $\mathrm{CVV}$ venoms. $P S S=0.90 \% \mathrm{NaCl} ; \mathrm{ACL}=A$. contortrix laticinctus venom $(2.0 \mu \mathrm{g} / \mathrm{g}) ;$ CVV $=C$. viridis viridis venom $(1.0 \mu \mathrm{g} / \mathrm{g}) ; \mathrm{pBPB}=$ parabromophenacyl bromide; $A x=$ Wyeth's Polyvalent (Crotalidae) Antivenom . Bars represent mean \pm S.E.M. $(n=4) . \quad$ * Indicates damage level significantly different at $p<0.05$ when compared to venom alone using Student's t-test. 


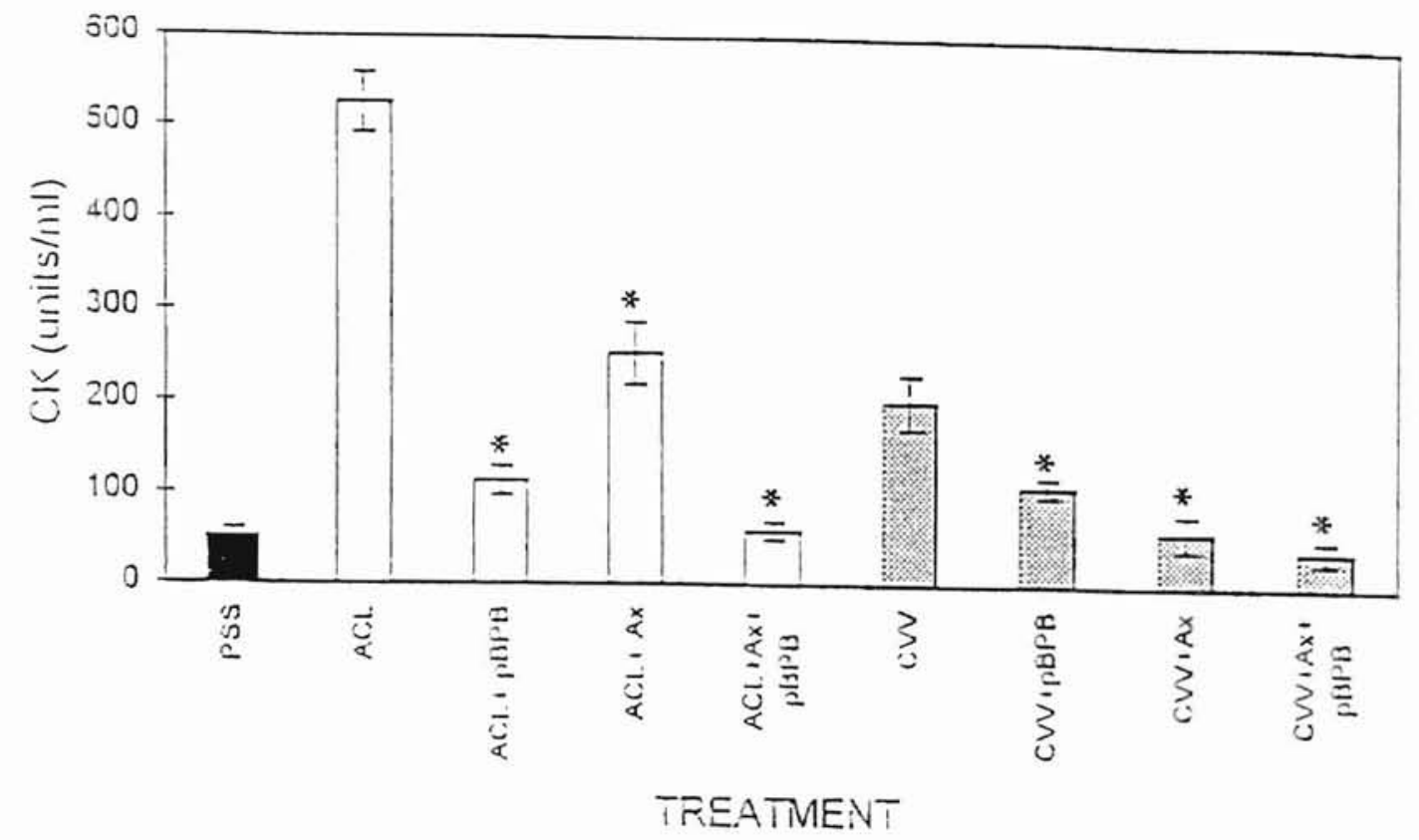

Figure 5: In vitro neutralization of myonecrosis induced by $A C L$ and CVV venoms. $P S S=0.90 \% \mathrm{NaCl} ; \mathrm{ACL}=A$. contortrix laticinctus venom $(2.0 \mathrm{ug} / \mathrm{g}) ; \mathrm{CVV}=C$. viridis viridis venom $(1.0 \mu \mathrm{g} / \mathrm{g}) ; \mathrm{pBPB}=$ parabromophenacyl bromide; $\mathrm{Ax}=$ Wyeth's Polyvalent (Crotalidae) Antivenom. Bars represent mean \pm S.E.M. $(n=4) . \quad$ * Indicates damage level significantly different at $p<0.05$ when compared to venom alone using Student's t-test. 


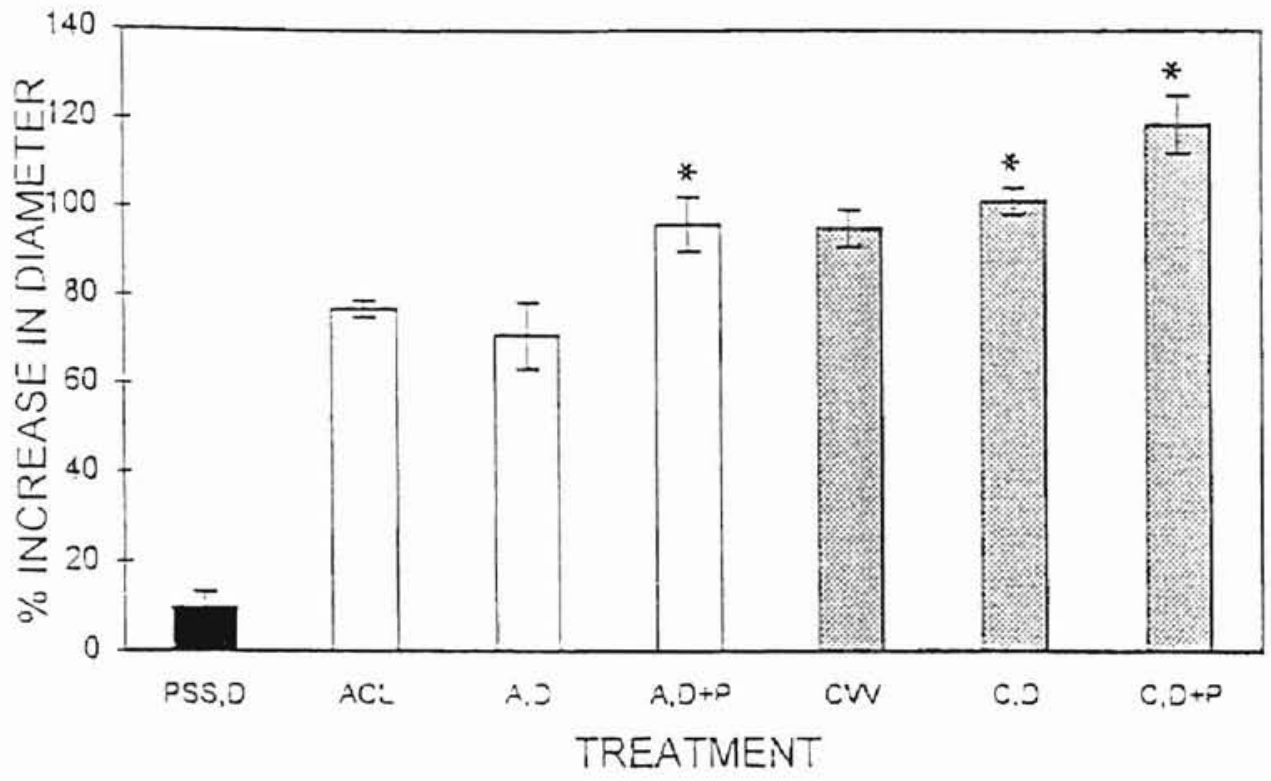

Figure 6: In vivo edema induced by $A C L$ and $C V V$ venoms followed by topical DMSO, with or without pBPB. PSS $=0.90 \% \mathrm{NaCl} ; \mathrm{ACL}(\mathrm{A})=A$. contortrix laticinctus venom $(2.0 \mu \mathrm{g} / \mathrm{g}) ; \mathrm{CVV}(\mathrm{C})=C$. viridis viridis venom (1.0ug/g); D = DMSO; $P$ = para-bromophenacyl bromide. Bars represent mean \pm S.E.M. $(n=6) .{ }^{*}$ Indicates damage level significantly different at $p<0.05$ when compared to venom alone using Student's t-test. 


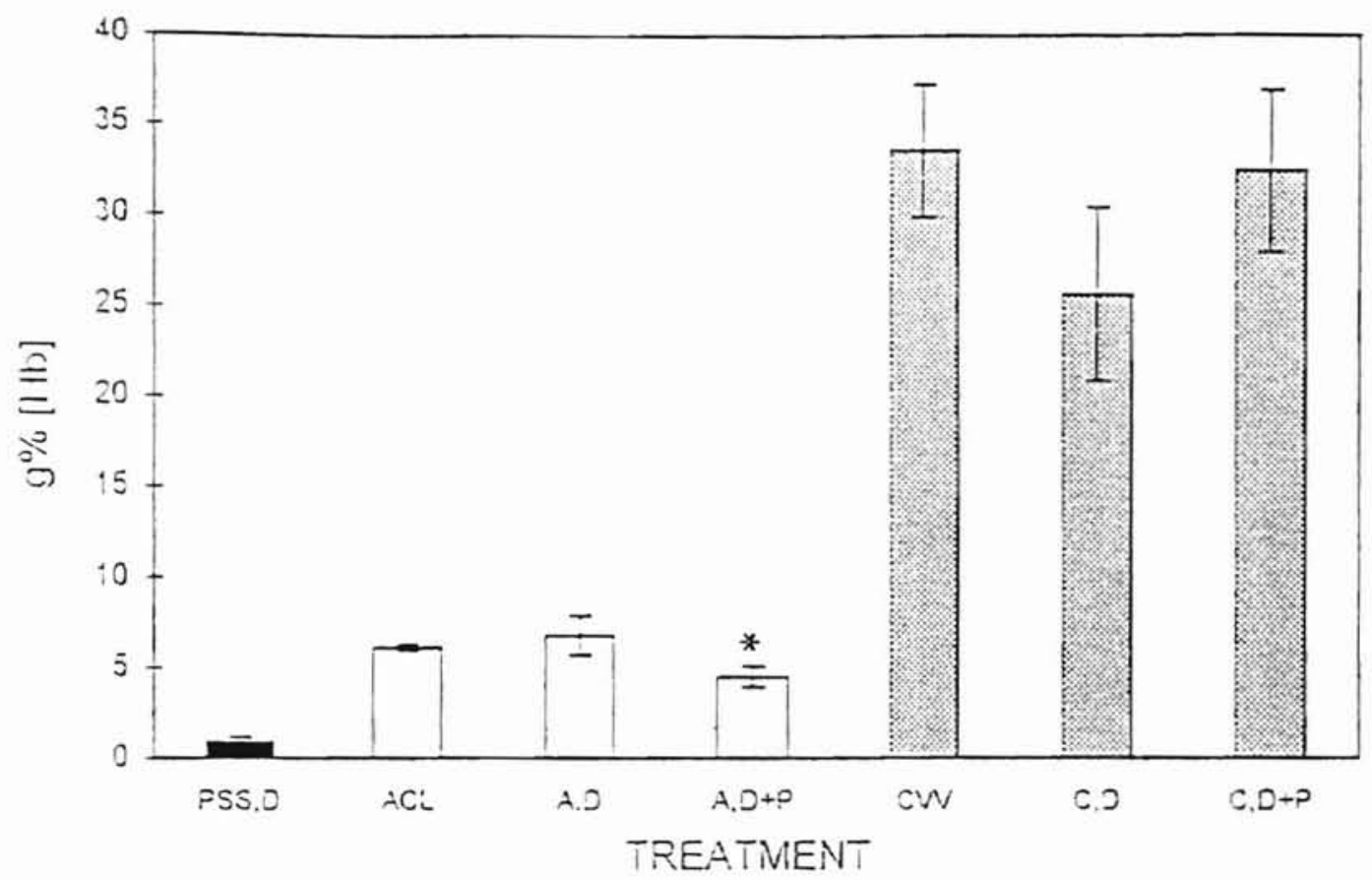

Figure 7: In vivo hemorrhage induced by $\mathrm{ACL}$ and $\mathrm{CVV}$ venoms followed by topical DMSO, with or without pBPB. PSS $=0.90 \% \mathrm{NaCl}$; $\mathrm{ACL}(\mathrm{A})=A$. contortrix laticinctus venom $(2.0 \mathrm{\mu g} / \mathrm{g}) ; \mathrm{CVV}(\mathrm{C})=C$. viridis viridis venom $(1.0 \mathrm{ug} / \mathrm{g}) ; D=D M S O ; P=$ para-bromophenacyl bromide. Bars represent mean $=$ S.E.M. $(n=6) . \quad$ * Indicates damage level significantly different at $p<0.05$ when compared to venom aione using Student's t-test. 


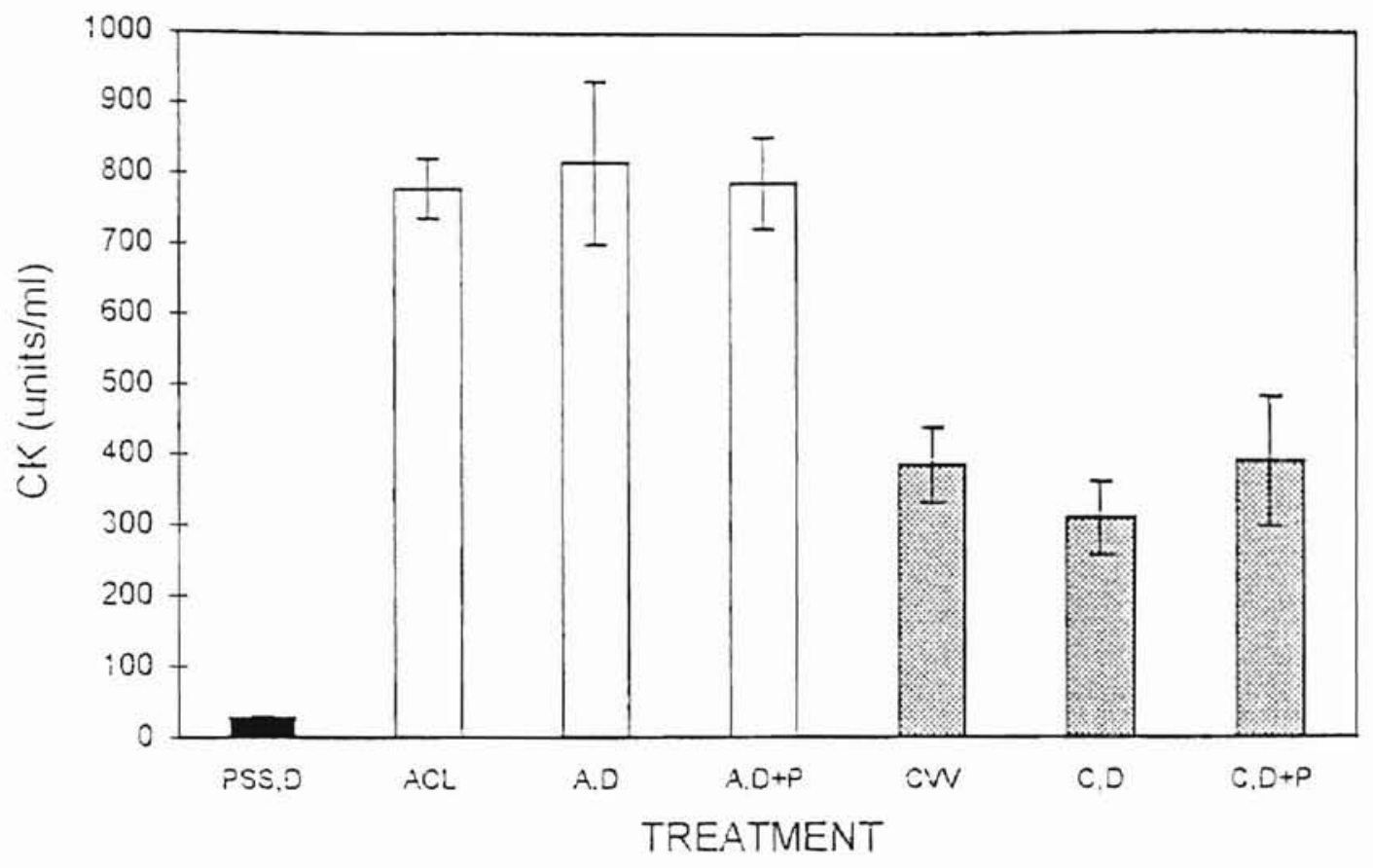

Figure 8: In vivo myonecrosis induced by $A C L$ and $C V V$ venoms followed by topical DMSO, with or without pBPB. PSS $=0.90 \% \mathrm{NaCl}$; $\mathrm{ACL}(\mathrm{A})=A$. contortrix laticinctus venom $(2.0 \mathrm{ug} / \mathrm{g}) ; \mathrm{CVV}(\mathrm{C})=\mathrm{C}$. viridis viridis venom $(1.0 \mu \mathrm{g} / \mathrm{g}) ; D=D M S O ; P=$ para-bromophenacyi bromide. Bars represent mean \pm S.E.M. $(n=6) . \quad$ * Indicates damage level significantly different at $p<0.05$ when compared to venom alone using Student's t-test. 


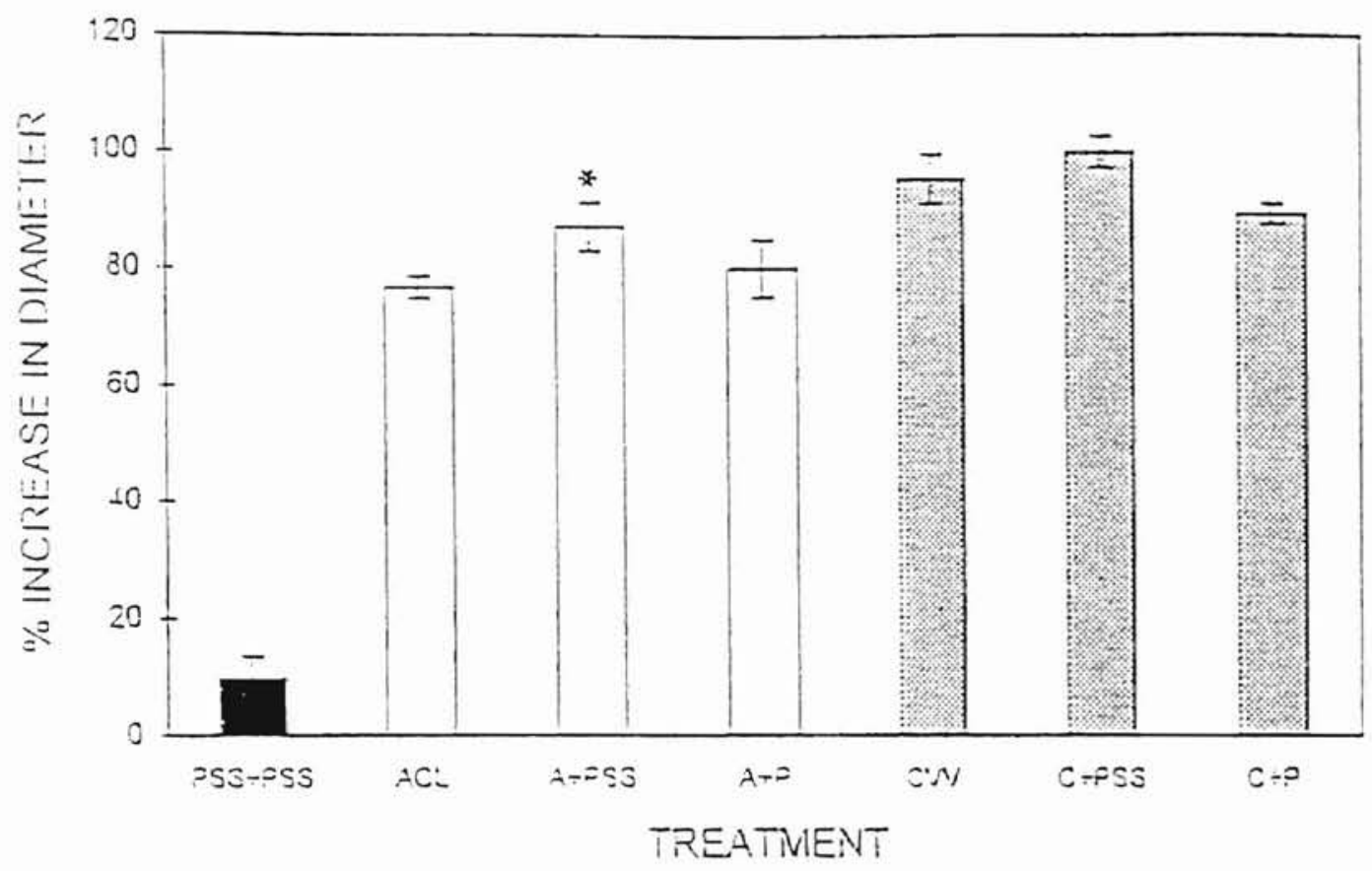

Figure 9: In vivo edema induced by $A C L$ and $C V V$ venoms followed by I.M. injection of PSS with or without pBPB. PSS $=0.90 \% \mathrm{NaCl} ; \mathrm{ACL}(\mathrm{A})=$ A. contortrix laticinctus venom $(2.0 \mathrm{ug} / \mathrm{g}) ; \mathrm{CVV}(\mathrm{C})=C$. viridis viridis venom $(1.0 \mu \mathrm{g} / \mathrm{g}) ; \mathrm{pBPB}=$ para-bromophenacyl bromide. Bars represent mean \pm S.E.M. $(n=6) .{ }^{*}$ Indicates damage level significantly different at $p<0.05$ when compared to venom alone using Student's t-test. 


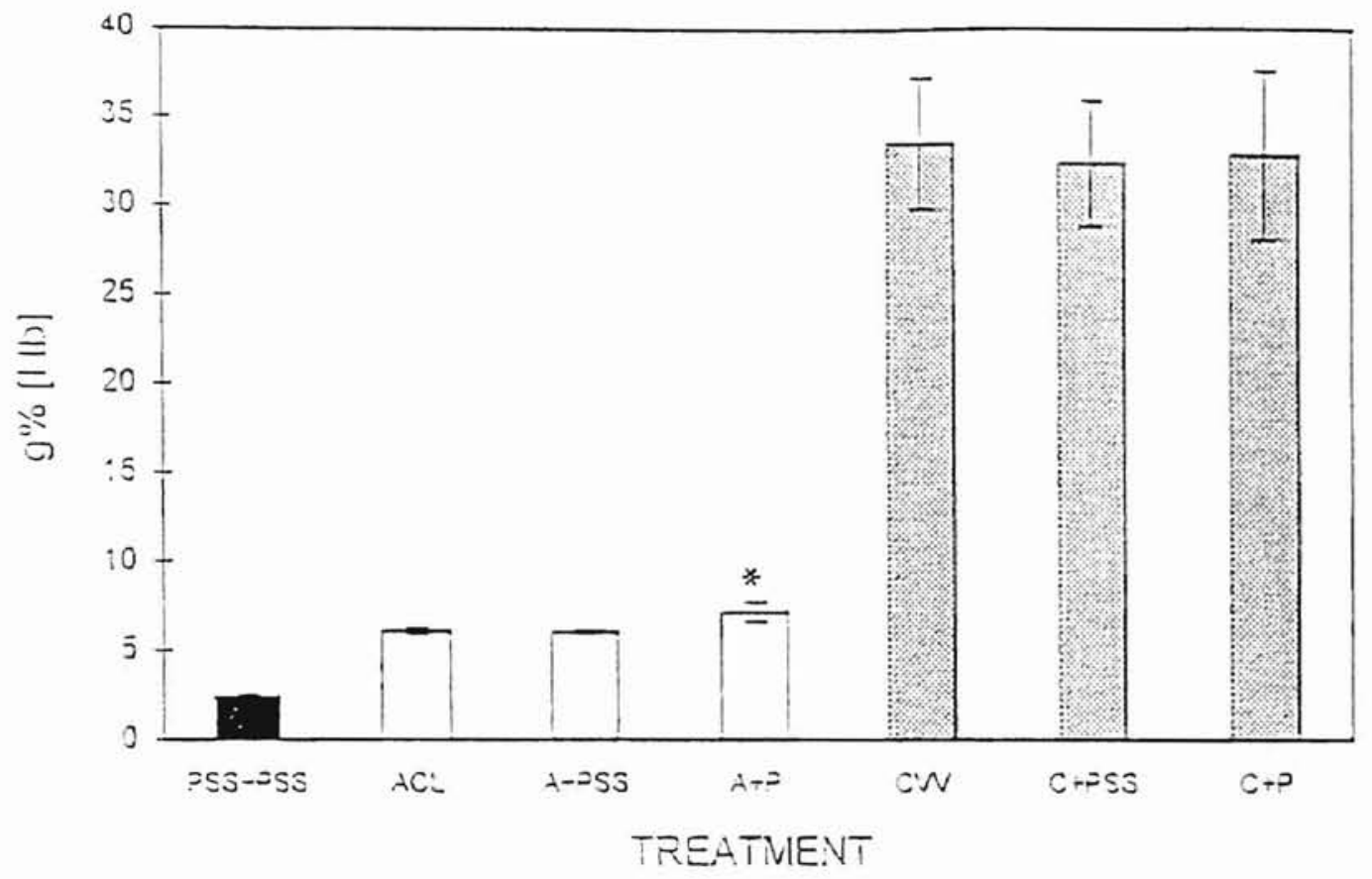

Figure 10: In vivo hemorrhage induced by $\mathrm{ACL}$ and $\mathrm{CVV}$ venoms followed by I.M. injection of PSS with or without pBPB. PSS $=0.90 \%$ $\mathrm{NaCl} ; \mathrm{ACL}(A)=A$. contortrix laticinctus venom $(2.0 \mathrm{ug} / \mathrm{g}) ; \mathrm{CVV}(C)=C$. viridis viridis venom $(1.0 \mathrm{\mu g} / \mathrm{g}) ; \mathrm{pBPB}=$ para-bromophenacyl bromide. Bars represent mean \pm S.E.M. $(n=6) . \quad$ * Indicates damage level significantly different at $p<0.05$ when compared to venom alone using Student's t-test. 


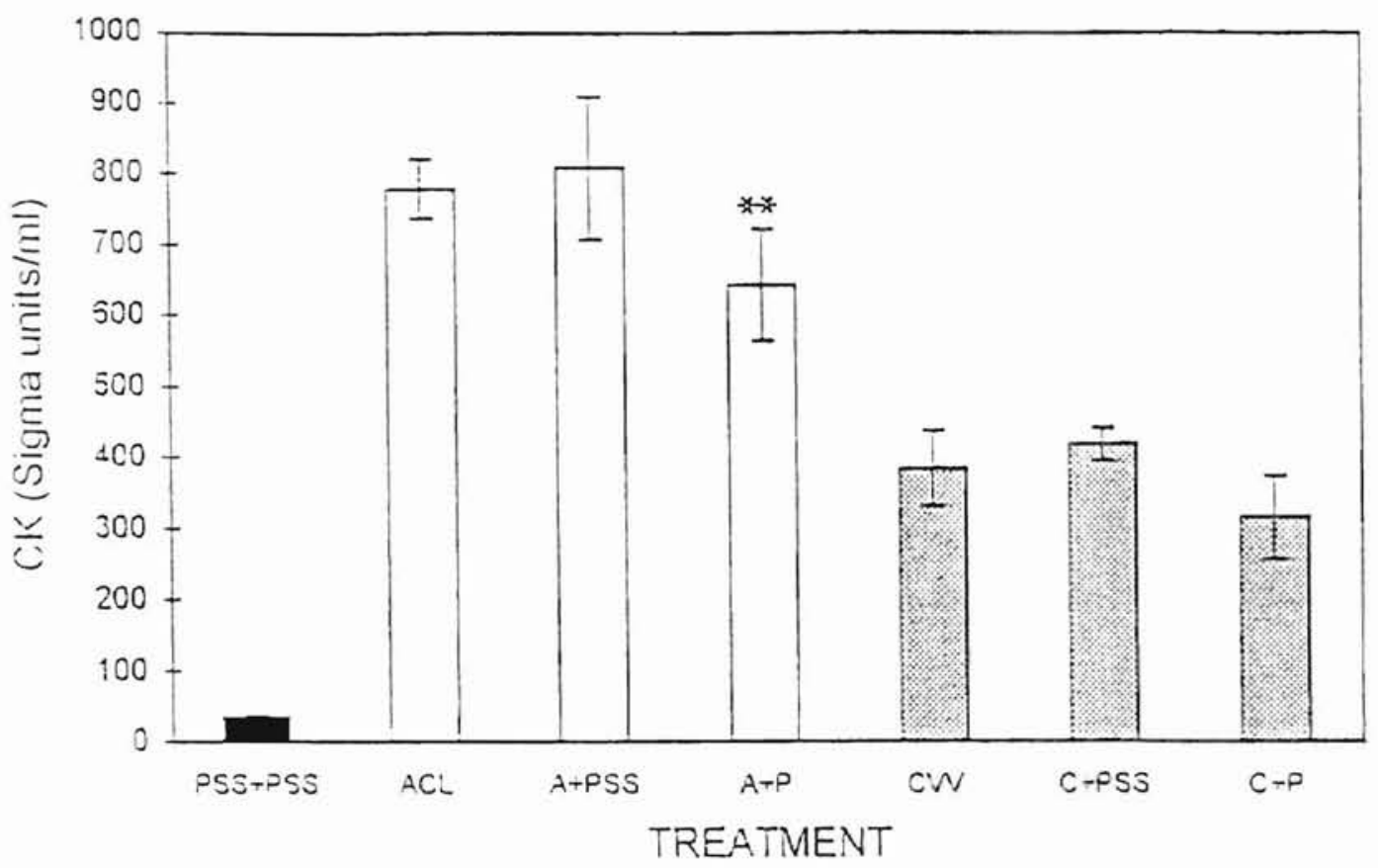

Figure 11: In vivo myonecrosis induced by $\mathrm{ACL}$ and $\mathrm{CVV}$ venoms followed by I.M. injection of PSS with or without pBPB. PSS $=0.90 \%$ $\mathrm{NaCl} ; \mathrm{ACL}(\mathrm{A})=A$. contortrix laticinctus venom $(2.0 \mathrm{ug} / \mathrm{g}) ; \mathrm{CVV}(C)=C$. viridis viridis venom $(1.0 \mathrm{ug} / \mathrm{g}) ; P=$ para-bromophenacyl bromide. Bars represent mean $=$ S.E.M. $(n=6) .{ }^{*}$ Indicates damage level significantly different at $p<0.05$ when compared to venom alone using Student's ttest. ${ }^{\star x}$ Indicates damage level significantly different at $p<0.1$ when compared to venom alone using Student's t-test. 


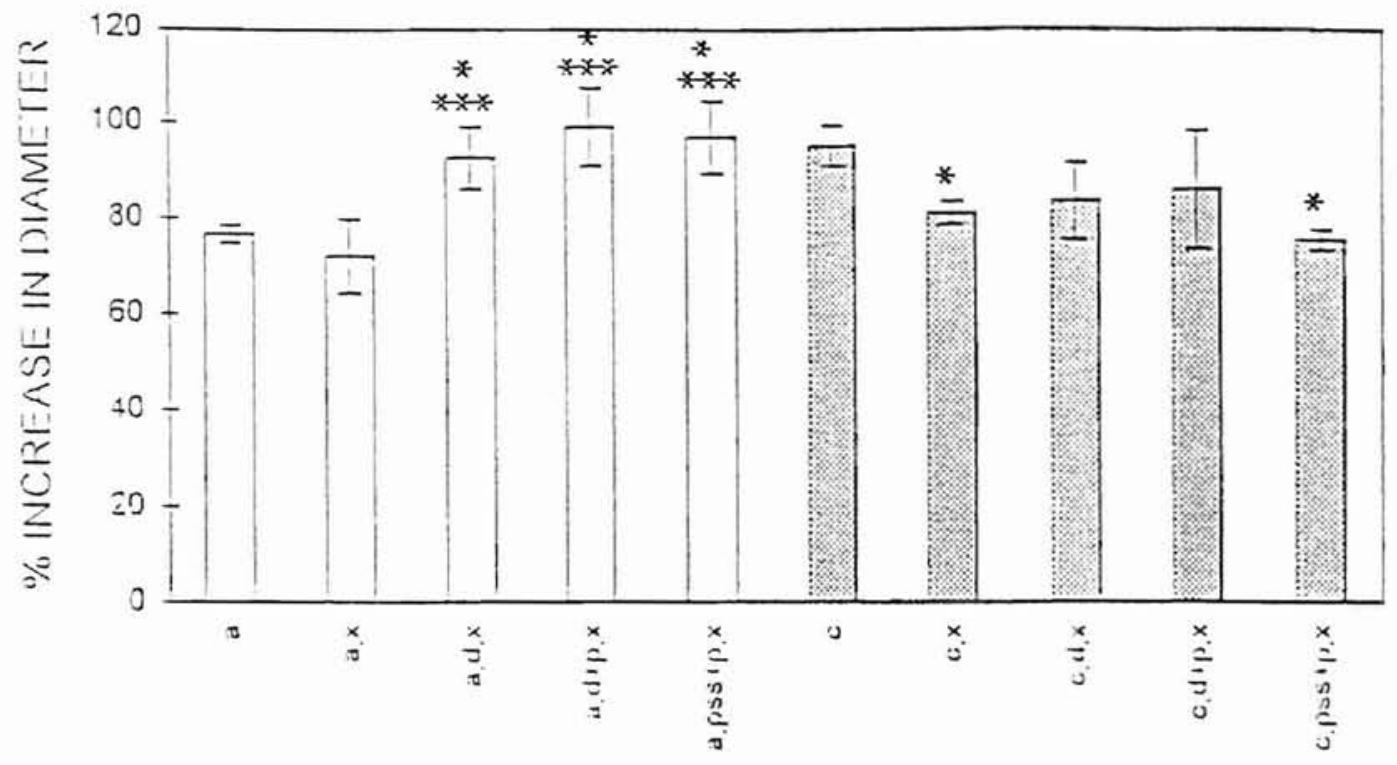

TREATINENT

Figure 12: In vivo edema induced by $\mathrm{ACL}$ and $\mathrm{CVV}$ venoms following topical and i.m. treatments and i.p. infusions of antivenom. pss $=0.90 \%$ $\mathrm{NaCl} ; \mathrm{a}=A$. contortrix laticinctus venom $(2.0 \mathrm{ug} / \mathrm{g}) ; \mathrm{c}=C$. viridis viridis venom $(1.0 \mu \mathrm{g} / \mathrm{g}) ; d=$ DMSO; $p=$ para-bromophenacyl bromide $(1 \mathrm{mg} / \mathrm{ml})$; $x=$ Wyeth's Polyvalent (Crotalidae) Antivenom. Bars represent mean \pm S.E.M. $(n=6) .{ }^{*}$ Indicates damage level significantly different at $p<0.05$ when compared to venom alone using Student's test. "** Indicates damage level significantly different at $p<0.05$ when compared to venom followed by antivenom using Student's t-test. 


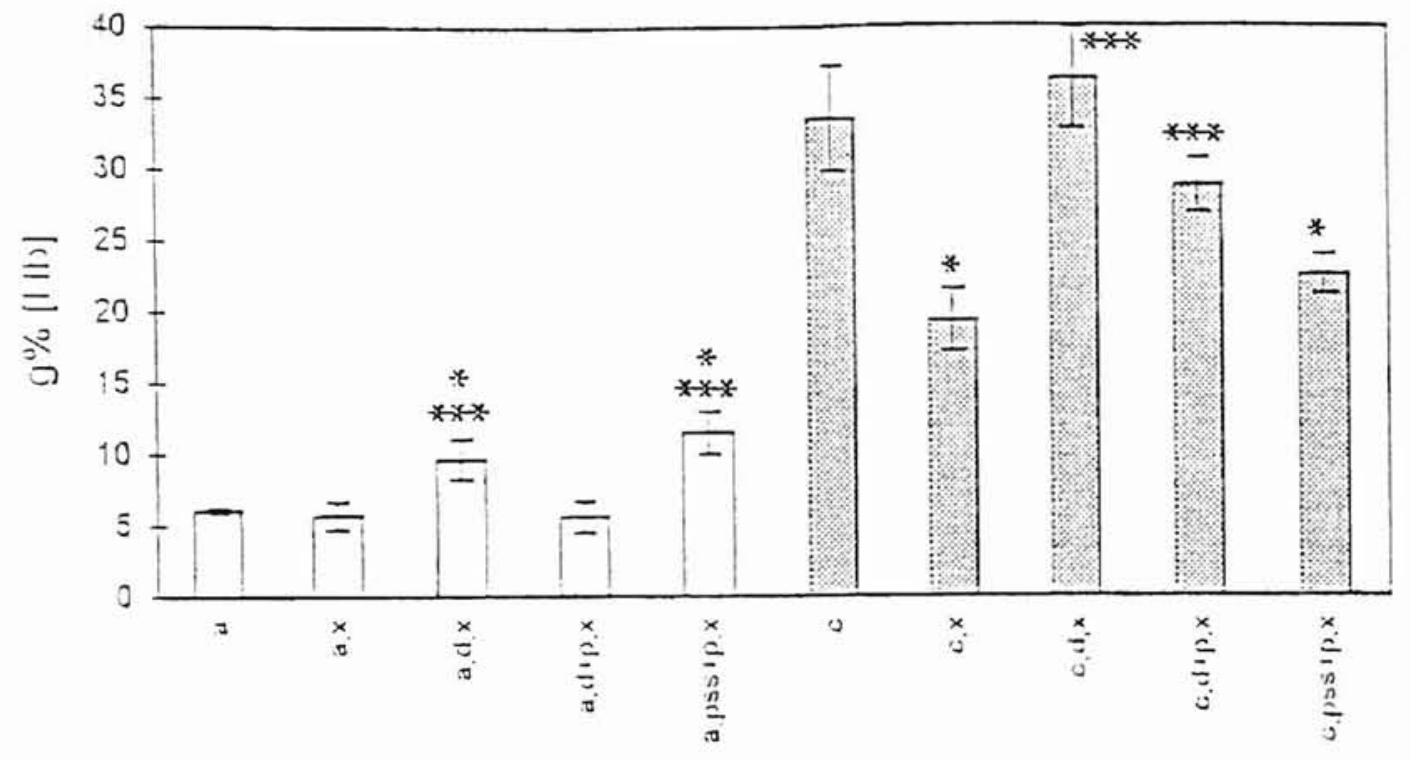

TREATMENT

Figure 13: In vivo hemorrhage induced by $\mathrm{ACL}$ and $\mathrm{CVV}$ venoms following topical and i.m. treatments and i.p. infusions of antivenom. pss = $0.90 \% \mathrm{NaCl} ; \mathrm{a}=A$. contortrix laticinctus venom $(2.0 \mathrm{ug} / \mathrm{g}) ; \mathrm{c}=C$. viridis viridis venom $(1.0 \mathrm{ug} / \mathrm{g}) ; d=$ DMSO; $p=$ para-bromophenacyl bromide $(1 \mathrm{mg} / \mathrm{ml}) ; \mathrm{x}=$ Wyeth's Polyvalent (Crotalidae) Antivenom. Bars represent mean \pm S.E.M. $(n=6) .{ }^{*}$ Indicates damage level significantly different at $p$ $<0.05$ when compared to venom alone using Student's t-test. ***Indicates damage level significantly different at $p<0.05$ when compared to venom followed by antivenom using Student's t-test. 


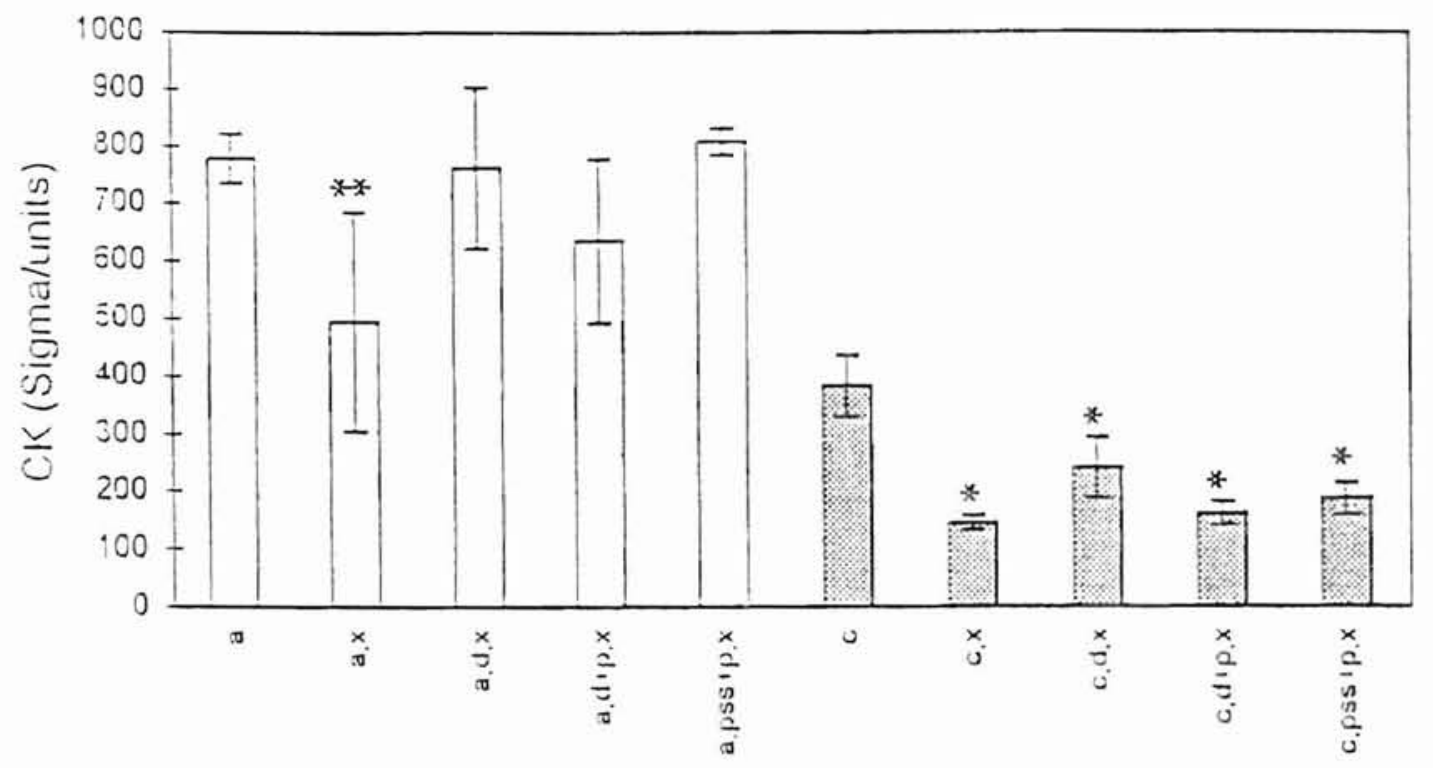

TREATMENT

Figure 14: In vivo myonecrosis induced by $A C L$ and $C V V$ venoms following topical and i.m. treatments and i.p. infusions of antivenom. pss $=0.90 \%$ $\mathrm{NaCl} ; \mathrm{a}=A$. contortrix laticinctus venom $(2.0 \mu \mathrm{g} / \mathrm{g}) ; \mathrm{c}=C$. viridis viridis venom $(1.0 \mu \mathrm{g} / \mathrm{g}) ; \mathrm{d}=$ DMSO; $\mathrm{p}=$ para-bromophenacyl bromide $(1 \mathrm{mg} / \mathrm{ml}) ; \quad \mathrm{x}=$ Wyeth's Polyvalent (Crotalidae) Antivenom. Bars represent mean $=$ S.E.M. $(n=6)$. Indicates damage level significantly different at $p<0.05$ when compared to venom alone using Student's t-test. ${ }^{* *}$ Indicates damage level significantly different at $p<0.1$ when compared to venom alone using Student's t-test. ${ }^{* \star *}$ Indicates damage level significantly different at $p<0.05$ when compared to venom followed by antivenom using Student's t-test. 


\section{CHAPTER 5}

\section{DISCUSSION}

Edema, hemorrhage and myonecrosis are common results of Crotalid envenomation and are often implicated in venomous encounters with the prairie rattlesnake (Crotalus viridis viridis) and the broad-banded copperhead (Agkistrodon contortrix laticinctus). The present study has shown that in comparing the venoms of Crotalus viridis viridis (CVV) and Agkistrodon contortrix laticinctus (ACL), the rattlesnake venom is more hemorrhagic than the copperhead venom, as the CVV venom induced 4 to 5 times the hemorrhage of $A C L$ venom despite being administered at half the dose of $A C L$ venom. Several hemorrhagic toxins have been identified in CVV venom including viriditoxin, (Fabiano and Tu, 1981) and two other high-molecular weight, 62 and $68 \mathrm{kDa}$, hemorrhagic toxins (Li et al., 1993). A low-molecular weight hemorrhagic toxin has been isolated from $A C L$ venom, $A C L$ hemorrhagic toxin I, but it is not responsible for all of the hemorrhagic activity as the crude venom demonstrated more activity than the purified hemorrhagic toxin alone (Johnson and Ownby, 1993b). The presence of more high-molecular weight hemorrhagic toxins in the CVV venom may account for the results of the present experiment, as the higher molecular weight hemorrhagic toxins are generally more potent (Bjarnason and Fox, 1994). The results of the hemorrhage assays in this experiment are consistent with Ownby et al. (1988), who reported massive 
hemorrhage as a result of CVV envenomation. Taking into account the difference in the experimental doses for $\mathrm{ACL}$ and $\mathrm{CVV}$ venom, both venoms caused about the same degree of myotoxicity. Both $A C L$ and $C V V$ venom have been shown to contain potent $\mathrm{PLA}_{2}$ myotoxins, $\mathrm{ACL}$ myotoxin (Johnson and Ownby, 1993a; Melo and Ownby, 1996) and CVV myotoxin (Ownby et al., 1997), respectively. In general, CVV venom also tended to generate more edema than $\mathrm{ACL}$ venom. The presence of toxins in $\mathrm{ACL}$ and $\mathrm{CVV}$ venoms that are directly responsible for edema formation have yet to be determined, but the increased hemorrhagic activity of CVV venom compared to $A C L$ venom may explain some of the greater amount of swelling induced by CVV venom. It should be noted that the gross appearance of edema seen in this experiment was different for the two venoms. ACL-induced edema appeared as a "puffy," serous-filled expansion of the limb that could be collapsed by slight pressure whereas, CVV-induced edema was not only sero-sanguinous, but also indurated, and could not be compressed by pressure. The type of edema produced by CVV venom is quite possibly related to this venom's increased hemorrhagic activity. Another possible explanation for the different manifestations of edema is the presence of different variants of $\mathrm{PLA} \mathrm{A}_{2}$ myotoxins in the two venoms. $\mathrm{ACL}$ myotoxin in $\mathrm{ACL}$ venom is enzymatically inactive, or shows very little enzymatic activity (Johnson and Ownby, 1993a) while CVV myotoxin in CVV venom is catalytically active (Ownby et al., 1997). Liu et al. (1991), Lomonte et al. (1993b), and Angulo et al. (1997) reported that PLA $\mathrm{P}_{2}$ myotoxins from the venoms of $T$. mucrosquamatus, $B$. asper and B. schlegelii, respectively, can cause the formation of edema, and that 
these toxins are $\mathrm{K}-49$, or lysine- $49 \mathrm{PLA}_{2}$ variants, the same as $\mathrm{ACL}$ myotoxin (Johnson and Ownby, 1993a). CVV myotoxin is a D49, or aspartate-49 PLA 2 (Ownby et al., 1997). The role of PLA $A_{2}$, and the presence or absence of catalytic activity, in edema-formation following envenomation is still controversial (Lloret and Moreno, 1993).

The present study also shows that samples for quantitating local tissue damage such as edema, hemorrhage and myonecrosis can be taken from the same animal, thus facilitating comparisons of these effects and their neutralization. Hemorrhage and myonecrosis were determined by measuring the $\mathrm{g} \%$ hemoglobin concentration of the affected muscle sample (Ownby et al., 1984 ) and the rate of release of CK from the envenomated muscle (Ownby et al., 1997), respectively. Edema was based on the relative increase in diameter of the envenomated lower hindlimb, similar to the measurements of the footpad, as described by Lomonte et al. (1993a). Usually, hemorrhage is measured using Kondo's method (Kondo et al., 1960) which requires an i.d. injection, not an i.m. injection as was done here. Although there are criticisms of measuring the extent of myonecrosis using the CK assay technique, Lomonte (1994) found that despite the number of alternative causes of elevated CK levels in serum, there is a dose-response correlation between venom-induced myonecrosis and CK levels. Ownby et al. (1982) compared CK assay and histological evaluation methods for measuring myonecrosis and found a highly significant correlation between these different assays at times of at least 3 hours after injection of venom. Initial increases in $\mathrm{CK}$ are due to muscle contraction, but $\mathrm{CK}$ release 
from muscle cells three hours post-injection of CVV venom is related to increases in permeability of the sarcolemma, which directly precedes vacuolation (Ownby et al., 1976).

The final experimental doses for ACL $(2.0 \mu \mathrm{g} / \mathrm{g})$ and CVV $(1.0 \mu \mathrm{g} / \mathrm{g})$ venom were chosen from the initial dose-response experiments not only because they approximated $\mathrm{ED}_{50}$ responses for each of the local tissue damage parameters but also because these doses are sub-lethal. Khole (1991) lists the i.m. LD $_{50}$ of ACL venom to be $20 \mu \mathrm{g} / \mathrm{g}$ and Ownby et al. (1985) lists the i.m. $\mathrm{LD}_{50}$ of $\mathrm{CVV}$ venom to be $3.0 \mu \mathrm{g} / \mathrm{g}$. It was important to use venom doses that were high enough to induce measurable edema, hemorrhage and myonecrosis, but still sub-lethal to correlate with the dose of venom injected in an actual snakebite. These final venom doses also induced levels of experimental tissue damage sufficient to allow neutralization to be detected, as indicated by the values obtained for edema, hemorrhage and myonecrosis in the Results Section.

In general, the combination of the antagonists, $p$-BPB and $A x$, with venom prior to injection resulted in significant reductions in edema, hemorrhage and myonecrosis for both venoms. Venom solutions that contained both $p$-BPB and antivenom showed a greater reduction of edema than when only one of the antagonist was incubated with the venom. Lack of reduction of edema in vitro by p-BPB alone may indicate that $\mathrm{PLA}_{2} \mathrm{~S}$ play only a minor role in direct edema formation. Since antivenom has been shown to reduce the edema-forming activity of $B$. asper venom (Lomonte, 1993a), a closely related snake, antivenom may be responsible for most of the reduction observed with $A C L$ and CVV 
venoms in the present study. Comparison of the results with the two venoms, in vitro, may also indicate that more than one type of toxin present in the venom is responsible for edema formation. That is, since hemorrhagic toxins affect the integrity of the capillary wall, which promotes the leakage of fluids into the extravascular space, they could also be indirectly responsible for subsequent edema. ACL and CVV contain hemorrhagic toxins (Johnson and Ownby, 1993b; Li et al., 1993) which are highly immunogenic (Ownby and Colberg 1987; Li and Ownby, 1996), and it has been shown that antivenom does have a high affinity for high molecular weight proteins, such as hemorrhagic toxins (Li and Ownby, 1996). The ability of antivenom to reduce edema could indicate that it is the hemorrhagic toxins producing the bulk of the edema. The increased reduction of edema seen when venom was mixed with both antivenom and $p$-BPB as compared to either antagonist alone could indicate that the inhibitors are neutralizing different venom components responsible for hemorrhage. However, since the reduction is more than additive, i.e., edema induced by either venom is reduced by about 70 percent when combined with both inhibitors, whereas reduction of edema caused by either venom is at best about 30 percent when mixed with only one of the antagonists, it is possible that the presence of $p$-BPB in the antivenom solution potentiates the neutralization by some other secondary factor such as a change in $\mathrm{pH}$ or an alteration in the structure of other venom components that makes them more susceptible to antivenom binding. Additional studies are needed to investigate this possibility. 
The ability of both $p$-BPB and antivenom to equally reduce hemorrhage induced by both venoms in vitro raises some interesting questions about the involvement of PLA $A_{2}$ in hemorrhage. It has been shown that hemorrhage is primarily the result of metalloproteinases (Bjarnason and Fox, 1988;1994). Both CVV (Li et al., 1993) and ACL (Johnson and Ownby, 1993b) contain these hemorrhagic toxins. However, nothing is known about the ability of $p$-BPB to inhibit such metalloproteinases. Perhaps the inhibition is due to a secondary effect such as a change in $\mathrm{pH}$ of the solution. Further experiments need to be done to determine the cause of this inhibition. It is possible that the PLA 2 are rupturing endothelial cell membranes as well as muscle cell membranes. In fact, Lomonte et al. (1994) showed that a PLA $\mathrm{P}_{2}$ myotoxin from $B$. asper venom damages endothelial cells in culture. It might be assumed that if the $p$-BPB was only neutralizing the PLA -induced hemorrhage, that the response of the $A x$ treated venom would be lower due to the inhibition of hemorrhagic toxins. However, since there is no difference in the reduction of hemorrhage between the two treatments, the question of whether or not the antagonist are "antagonizing" the same components is raised. It would be interesting to test $p$ BPB's ability to neutralize purified hemorrhagic toxins from these venoms.

All treatments showed a significant reduction in myonecrosis when $p$-BPB and Ax were individually mixed with the venom prior to injection, but tests showed even greater neutralization when the two antagonists were used in combination. The reduction of myonecrosis in the $p$-BPB treatment indicates that $\mathrm{PLA}_{2}$ myotoxins from both venoms were neutralized. The lack of total 
neutralization of myonecrosis indicates that there are other non-PLA $A_{2}$ toxins present in these crude venoms that are responsible for muscle damage, such as myotoxin a in CVV venom (Ownby et al., 1976). The results also demonstrate that some of the venom components are not neutralized by commercial antivenom. Ownby et al. $(1983 ; 1985)$ showed that Wyeth's Polyvalent (Crotalidae) antivenom did not neutralize myonecrosis induced by myotoxin a from CVV venom, nor does the antivenom have antibodies to myotoxin a (Ownby et al., 1983). Interestingly, Ownby et al. (1986) found that antimyotoxin a serum neutralized more myonecrosis induced by CVV crude venom than the commercial polyvalent antivenom. The previous results are supported by the further reduction of myonecrosis when venom was treated with $p$-BPB and $\mathrm{Ax}$ found in the present study. Thus, Wyeth's Polyvalent (Crotalidae) antivenom is perhaps inhibiting other toxins not inhibited by $p$-BPB. It could be that the commercial polyvalent antivenom is reducing myonecrosis caused by vascular damage and subsequent ischemia, by antagonizing the hemorrhagic toxins. Ownby et al. (1988) indicated that a large portion of the myonecrosis induced by CVV venom was a result of hemorrhage and subsequent ischemia.

In general, with the exception of mice receiving i.p. infusions of antivenom, those mice getting injections of venom followed by topical or i.m. DMSO- $p$-BPB or saline- $p$-BPB, respectively, showed no significant reductions in local tissue damage. However, hemorrhage induced by ACL venom was significantly reduced in vivo by topical DMSO-p-BPB. This result is consistent with the results from the in vitro tests with the same antagonist. It is possible that 
the $p$-BPB is inhibiting hemorrhage induced by the PLA $A_{2}$ activity of $A C L$ venom. However, the increase in hemorrhage as a result of saline-p-BPB treatment following injection of $\mathrm{ACL}$ venom points again to the caustic nature of the $p$-BPB suspension versus the $p$-BPB solution.

Both the DMSO- $p$-BPB and satine- $p$-BPB treatments failed to show any reduction in the edema-forming activity of the venom. This lack of inhibition is probably due to the inability of the antagonist to the reach the venom, in vivo, or to reverse already existing edema. The significant rises in edema seen in the DMSO treatments are most likely due to the increased spread of the venom associated with the increased vascular permeability caused by the DMSO itself. The effectiveness of DMSO to reduce local tissue damage, especially hemorrhage, is contradictory. Tu et al. (1970) and Ownby et al. (1975) reported DMSO itself to be effective at neutralizing Crotalid induced hemorrhage in vitro but not in vivo. In the present study, it was used for its action as a transcutaneous vehicle for $p-\mathrm{BPB}$, with the hope that it would transport more antagonist than venom. The adverse effects of DMSO have been previously described in Tu et al. (1970). As these previous experiments reported the inability of DMSO to inhibit hemorrhage in vivo, it is not known which hemorrhagic components of venom the DMSO is affecting in in vitro experiments. Further experiments that test the in vitro capacity of DMSO alone to neutralize venom $\mathrm{PLA}_{2} \mathrm{~S}$ need to be performed. The increases in edema with saline- $p$-BPB treatment are possibly a result of the fact that the injected fluid in this case was, in fact, a suspension and not a solution. $p$-BPB is not readily 
soluble in saline. It is possible that the non-dissolved $p$-BPB particles were inducing an inflammatory response themselves.

The inability of any topical or i.m. treatment to reduce myonecrosis induced by myotoxins may be primarily a problem of time, as the venoms produce almost immediate muscle damage upon injection. Johnson and Ownby (1993a) showed that ACL myotoxin injected i.m. induced rapid myonecrosis of murine muscle cells appearing within 15 minutes. Ownby et al. (1997) also noted that CVV myotoxin produces rapid onset of myonecrosis, with lesions appearing within three hours. However, both $\mathrm{ACL}$ and $\mathrm{CVV}$ myotoxins induce myonecrosis within 5 minutes of injection (Ownby, personal communication). The myonecrosis due to myotoxin $a$ is measured in hours, not minutes, as with the PLA $\mathrm{A}_{2}$ myotoxins (Melo and Ownby, 1996). Lomonte et al. (1993b) also showed that myonecrosis induced by the PLA $A_{2}$ myotoxin from $B$. asper, Myotoxin II, was seen only 3 to 4 minutes after application. Apparently, the topical DMSO- $p$-BPB or saline- $p$-BPB cannot reach the site fast enough to prevent damage.

The concept of a time variable might also factor into the ability of $p$-BPB to neutralize some PLA $A_{2}$-induced hemorrhage because of the idea that the PLA 2 myotoxins probably do not directly bind to endothelial cells via receptors, but rather indirectly hydrolyze the plasma membrane of vessel walls. This indirect process probably takes more time than direct ligand binding reactions. However, Lomonte et al. (1993b) reported that the PLA $\mathrm{A}_{2}$ myotoxin from $B$. asper venom 
caused extensive plasma leakage from capillaries within 5 minutes after experimental application.

In previous studies, antivenom has not been shown to effectively reduce local tissue damage, even if administered immediately following experimental envenomation (Russell, 1973; Ownby et al., 1983; Rucavado and Lomonte, 1996). However, in the present study, antivenom (i.p.) significantly reduced edema, hemorrhage and myonecrosis induced by CVV venom. Addition of $p$ BPB (in saline, i.m.) treatment did not provide any additional reduction in antivenom treated animals. Thus, it is likely that antivenom is responsible for all of the in vivo reduction of edema observed with CVV venom. The lack of change in edema formation seen in those mice treated with DMSO- $p$-BPB and antivenom following injection of CVV venom again suggests that DMSO itself promotes edema by increasing the spread of the venom. Perhaps, the lack of a significant increase in edema in this case is a result of antivenom negating the extra edema formation generated by the DMSO, instead of reducing edema as seen in mice receiving CVV venom followed by only antivenom.

Similar to the edema results, mice treated with antivenom alone and i.m. saline-p-BPB followed by antivenom after injection of CVV venom showed significant reductions of hemorrhage. Again, as with edema, antivenom, not $p$ BPB alone was probably responsible for the neutralization. Antivenom also negated the increase in hemorrhage produced by the increased spread of the venom using the DMSO, resulting in no change of hemorrhagic activity, instead of reducing the hemorrhage as seen by treating mice only with antivenom 
following injections of CVV venom. Such similar results of edema and hemorrhage activity following injections of CVV venom followed by antivenom suggests that the hemorrhagic toxins are responsible for a large portion of the edema.

Antivenom also reduced myonecrosis induced by CVV venom. All treatments which included $A x$ with topical DMSO-p-BPB and i.m. saline- $p$-BPB significantly reduced CVV-induced myonecrosis. Neutralization of the hemorrhagic components, which are abundant in the CVV venom, may be responsible for the decrease in myonecrosis seen in CVV treated with antivenom, in vivo. Hemorrhagic toxins produce vascular damage that can eventually produce ischemia leading to indirect muscle damage (Ownby et al., 1978; Harris and Cullen, 1990). These toxins require more time to induce this type of myotoxic damage, as opposed to the direct action of myotoxins destroying muscle cells, and therefore provides the time necessary for antivenom to partially inhibit the myonecrosis. Ownby (1990) reported muscle damage due to ischemia occurring about 4 to 6 hours after injection of some hemorrhagic toxins.

Similar results were seen with hemorrhage induced by both venoms. Hemorrhage induced in mice treated with topical DMSO-p-BPB and i.m. saline-p$\mathrm{BPB}$ and antivenom following injection of $\mathrm{ACL}$ venom significantly rose compared to mice injected only with $\mathrm{ACL}$ venom. Just as in the experimental treatments receiving i.m. saline- $p$-BPB but not antivenom, the hemorrhage significantly increased. Typically, neither the topical or i.m. treatments, whether 
followed by antivenom or not, produced any significant changes in myonecrosis induced by $A C L$ venom.

In comparing the different injection protocols, combining the venom with the antagonist (in vitro) prior to injection proved to be much more effective than administering the venom and antagonists separately (in vivo). These results are consistent with the previous studies by Ownby et al. (1975), Melo et al. (1993) and Melo et al. (1994) and others working with non-crotalid venom, that also showed that mixing venom with various antagonists prior to injection provided greater neutralization of local tissue damage than when antagonist were given after injection of venom. In both the in vitro and in vivo experiments, antivenom tended to show an overall greater reduction of local tissue damage than $p$-BPB. But in most cases, there were differences in reductions using the antagonists together that showed more than the additive effects of reduction seen by using the $p$-BPB or antivenom separately. Such synergistic effects could be the result of secondary factors such as a change in $\mathrm{pH}$ that enhances the neutralization capacity of either the $p$-BPB or the antivenom, or that the $\mathrm{pH}$ shift itself is neutralizing venom components. The next set of experiments should study the effect of both of these compounds on the individual (purified) hemorrhagic and myotoxic components, as opposed to the crude venoms, to try to quantify the amount of local tissue damage produced by each type of toxin. In the present work, mice which were treated with a topical or i.m. injected antagonist plus antivenom had no less amount of local tissue damage when compared to mice 
which were treated with only antivenom. In fact, all of the significant changes were increases in local tissue damage.

In conclusion, antivenom appears to be the best antagonist available for treating CVV-induced edema, hemorrhage and myonecrosis. However, it is not very effective for $\mathrm{ACL}$ venom. For antagonist such as $p$-BPB, new methods of transcutaneous penetration need to be explored to enhance their access to venom components. 


\section{REFERENCES}

Angulo, Y., Chaves, E., Alape, A., Rucavado, A., Gutierrez, J.M., and Lomonte, B. (1997) Isolation and characterization of a myotoxic phospholipase $A_{2}$ from the venom of the arboreal snake Bothriechis (Bothrops) schlegelii from Costa Rica. Ach. Biochem. Biophys. 339, 260-266.

Araujo, H.S.S., White, S.P., Ownby, C.L. (1996) cDNA cloning and sequence analysis of a lys 49 phopholipase $\mathrm{A}_{2}$ myotoxin from Agkistrodon contortrix laticinctus snake venom. Ach. Biochem. Biophys. 326, 21-30.

Arnold, R.E. (1982) Treatment of rattlesnake bites. In: Rattlesnake Venoms: Their Actions and Treatments (Tu, A.T., Ed). New York: Marcel Dekker, Inc., pp. 163-210.

Bjarnason, J.B. and Fox, J.W. (1988) Hemorrhagic toxins from snake venoms. J. Toxicol.-Toxin Reviews. 7, 121-209.

Bjarnason, J.B. and Fox, J.W. (1994) Hemorrhagic metalloproteinases from snake venom. Pharmac. Ther. 62, 325-372.

Burch, J., Agrival, R., Mattox, K., Feliciano, D., and Jordan, G. (1988) The treatment of Crotalid envenomation without antivenom. J. Trauma 28, 35-42.

Cameron, D. L. and Tu, A. T. (1977) Characterization of myotoxin a from the venom of Prairie rattlesnake (Crotalus viridis viridis). Biochemistry 16, 25462553. 
Chippaux, J.P. and Goyffon, M. (1991) Production and use of snake antivenin.. In: Handbook of Natural Toxins, Vol. 5, Reptile Venoms and Toxins, (Tu, A.T.,Ed.). New York: Marcel Dekker. pp. 529-556

Consroe, P., Egen, N.B., Russell, F.E., Gerrish, D. C., Smith, K., Sidiki, A., Landon, J.T. (1995) Comparison of a new ovine antigen binding fragment $F(a b)$ antivenin for United States Crotalidae with the commercial antivenin for protection against venom-induced lethality in mice. Am. J. Trop. Med. Hyg. 53, 507-519.

Cunningham, E.R., Sabback, M.S., Smith, M.R., and Fitts, C.T. (1979) Snakebite: role of corticosteroids as immediate therapy in an animal model. Am. Surg. 45, 757-759.

Dart, R.C. and Horowitz, R.S. (1996) Use of antibodies as antivenoms: A primative solution for a complex problem? In: Envenomings and Their Treatments, Bon C and Goyffon M (Eds). Pasteur Institute, Paris, pp. 83-94.

Dufton, M.J. and Hider, R.C. (1993) Conformational properties of the neurotoxins and cytotoxins isolated from the elapid snake venoms. Crit. Rev. Bioch. 14, 113-171.

Fabiano, R.J. and Tu, A.T. (1981) Purification and biochemical study of viriditoxin: tissue damaging toxin from the prairie rattlesnake venom. Biochemistry 20, 21-27.

Fletcher, J.E., Araujo, H.S.S., and Ownby, C.L. (1997) Molecular events in the myotoxic action of phospholipases. In: Venom Phospholipase A2 Enzymes: Structure, Function and Mechanism. Kini, R.M., (Ed) John Wiley and Sons Ltd. pp. 455-497. 
Fox, J.W., Elzinga, M. and Tu, A.T. (1979) Amino acid sequence and disulfide bond assignment of myotoxin a isolated from the venom of prairie rattlesnake. Biochemistry 18, 678-684.

Gleason, M.L., Odell, G.V., and Ownby, C.L. (1983) Isolation and biological activity of viriditoxin and a viriditoxin variant from Crotalus viridis viridis venom. Toxicon Rev. 2, 235.

Gold, B.S. (1996) Alternative treatment modalities in the management of poisonous snake bites. In: Envenomings and Their Treatments, Bon, C. and Goyffon, M. (Eds). Pasteur Institute, Paris, pp. 63-76.

Gomez, H.F. and Dart, R.C. (1995) Clinical toxicology of snakebites in North America. In: Handbook of Clinical Toxicology of Animal Venoms and Poisons. Meier $J$ and White $J$ (Eds). CRC Press, Boca Raton, pp. 1-8.

Gonzalez, D. (1991) Snakebite problems in Europe. In: Handbook of Natural Toxins, Vol. 5, Reptile Venoms and Toxins, Tu, AT(Ed.). New York: Marcel Dekker. pp. 3-52

Grandgeorge, M., Vernon, J.L., Lutsch, M.F., Riffard, P., Pepin, S., and Sherrmann, J.M. (1996) Preparation of improved F(ab')2 antivenoms. An example: new polyvalent European viper antivenom (equine). In: Envenomings and Their Treatments, Bon C and Goyffon M (Eds). Pasteur Institute, Paris, pp. 161-172.

Guderian, R., MacKenzie, C., and Williams, J. (1986) High voltage treatment for snakebite. Lancet 2, 229.

Gutierrez, J.M. and Lomonte, B. (1989) Local tissue damage induced by Bothrops snake venom: a review. Mem. Inst. Butantan 51, 211-223. 
Gutierrez, J.M., Rojas, G., Bogarin, G., and Lomonte, B. (1996) Evaluation of the neutralizing ability of antivenoms for the treatment of snake bite envenoming in Central America. In: Envenomings and Their Treatments, Bon, C. and Goyffon, M. (Eds). Pasteur Institute, Paris, pp. 223-234.

Hardy, D. (1992) A review of first aid measures for pit viper bites in North America with a appraisal of extractor suction and stun gun electroshock. In: Biology of the PitVipers. Campbell and Brodies (Eds.) Arlington: Selva Publishing. pp. 405-415.

Harris, J.B. and Cullen, M.J. (1990) Muscle necrosis caused by snake venoms and toxins. Electron Microsc. Rev. 3: 183-211.

Hite, L.A., Fox, J.W., and Bjarnason, J.B. (1992) A new family of proteinases is defined by snake venom metalloproteinases. Biol. Chem. Hoppe-Seyler 373 , 381-385.

Howe, R. (1988) Electric shock does not save snakebitten rats. Ann Emerg. Med. 17, 254-256.

Johnson, E.K., and Ownby, C.L. (1993a) Isolation of a myotoxin from the venom of Agkistrodon contortrix laticinctus (Broad-banded Copperhead) and pathogenesis of myonecrosis induced by it in mice. Toxicon. 31, 243-255.

Johnson, E.K., and Ownby, C.L. (1993b) Isolation of a hemorrhagic toxin from the venom of Agkistrodon contortrix laticinctus (Broad-banded Copperhead) and pathogenesis of the hemorrhage induced by the toxin in mice. Toxicon. 25, 267-278. 
Khole, Vijay. (1991) Toxicities of snake venoms and their components. In Handbook of Natural Toxins, Vol. 5, Reptile Venoms and Toxins, Tu, A.T.(Ed.). New York: Marcel Dekker, pp. 405-470.

Kini, M.R., and Evans, H.J. (1989) A model to explain the pharmacological effects of snake venom phospholipases $A_{2}$. Toxicon 27, 613-635.

Kondo, H., Kondo, S., Ikezawa, H., Murata, R., and Ohsaka, A. (1960) Studies on the quantitative method for determination of hemorrhage activity of Habu Snake venom. Jap. J. Med. Sci. Biol. 13, 43-51.

Kroegel, C. and Meyer zum Buschenfelde, K.H. (1986) Biological basis for highvoltage shock treatment for snakebite. Lancet 2, 1335.

Landon, J. and Smith, D.C. (1996) Development of novel antivenoms based on specific ovine Fab. In: Envenomings and Their Treatments, Bon C and Goyffon M (Eds). Pasteur Institute, Paris, pp. 173-182.

Laure, C. (1975) The primary structure of crotamine. Hoppe-Seyler's Z. Physiol. Chem. 356, 2134-215.

Lee, C.Y., Lee, S.Y., Chen, Y.M. and Lin, W.W. (1985) On the causes of death due to toxic phospholipase $A_{2}$ from snake venoms. Toxicon 23, 585.

Lerner, R.A. (1982) Tapping the immunological repetoire to produce antibodies of predetermined specificity. Nature 299, 592-596.

Li, Q., Colberg, T.R. and Ownby, C.L. (1993) Cross-reactivities of monoclonal antibodies to a myotoxin from the venom of the braod-banded copperhead (Agkistrodon contortrix laticinctus). Toxicon 31, 1187-1196. 
Li, Q. and Ownby, C.L. (1996) Immunological studies of rabbit antibodies against hemorrhagic fractions of Crotalus viridis viridis venom: role of crossreacting antibodies in neutralization. Comp. Biochem. Physiol. 114A, 167-173.

Litovitz, T.I., Holm, K.C., Bailey, K.M., and Schmitz, B.F. (1991) Annual report of the American Association of Poison Control Centers National Data Collection System. Am. J. Emerg. Med. 10, 452-505.

Liu, C.S., Chen, J.M., Chang, C.H., Chen, S.W., Teng, C.M., and Tsai, I.H. (1991) The amino acid sequence and properties of an edema-inducing lys 49 phospholipase $\mathrm{A}_{2}$ homolog from the venom of Trimeresurus mucrosquamatus. Biochim. Biophys. Acta. 1077, 362-370.

Lloret, S. and Moreno, J.J. (1993) Oedema formation and degranulation of mast cells by phospholipases $A_{2}$ purified from porcine pancreas and snake venoms. Toxicon 31, 949-956.

Lomonte, B. (1994) Tissue damage and inflammation induced by snake venoms. Ph.D. Dissertation. Goteborg, Sweden., pp. 1-28.

Lomonte, B., Gutierrez, J. M., Moreno, E., Cerdas, L. (1987) Antibody neutralization of a myotoxin from Bothrops asper (terciopelo). Toxicon 25, 443

Lomonte, B. and Gutierrez, J.M. (1989) A new muscle damaging toxin, myotoxin II, from the venom of the snake Bothrops asper (tercipelo). Toxicon 25, 443-449.

Lomonte, B., Gutierrez, J.M., Carmona, E., and Rovira, M.E. (1990) Equine antibodies to Bothrops asper myotoxin II: isolation from polyvalent antivenom and neutralizing ability. Toxicon $28,379-384$. 
Lomonte, B., Tarkowski, A., and Hanson, L. (1993a) Host response to Bothrops asper snake venom: analysis of edema formation, inflammatory cells, and cytokine release in a mouse model. Inflammation. 17, 93-105.

Lomonte, B., Lundgren, J., Johansson, B., and Bagge, U. (1993b) The dynamics of local tissue damage induced by Bothrops asper snake venom and myotoxin II on the mouse cremaster muscle: and intravital and electron microscopic study. Toxicon 32, 41-55.

Lomonte, B., Gutierrez, J.M., Borkow, G., Ovadia, M., Tarkowski, A. and Hanson, L.A. (1994) Activity of hemorrhagic metalloproteinase $\mathrm{BaH}-\mathrm{i}$ and myotoxin II from Bothrops asper snake venom on capillary endothelial cells in vitro. Toxicon

Mebs, D. and Ownby, C.L. (1990) Myotoxic components of snake venoms: their biochemical and biological activities. Pharmac. Ther. 48, 223-236.

Meier, J. (1995) Venomous and Poisonous animals - a biologist's view. In: Handbook of Clinical Toxicology of Animal Venoms and Poisons. Meier $\mathrm{J}$ and White J (Eds). CRC Press, Boca Raton, pp. 1-8.

Melo, P.A. and Suarez-Kurtz, G. (1988) Release of sarcoplasmic enzymes from skeletal muscle by Bothrops jararacussu venom: antagonism by heparin and by the serum of South American marsupials. Toxicon 31, 285-291.

Melo, P.A., Homsi-Brandeburgo, M.I., Giglio, J.R. and Suarez-Kurtz, G. (1993) Antagonism of the myotoxic effects of Bothrops jararacussu venom and bothropstoxin by polyanions. Toxicon. 31, 285-291. 
Melo, P.A., do Nascimento, M.C., Mors, W.B., and Suarez-Kurtz, G. (1994) Inhibition of the myotoxic and hemorrhagic activities of Crotalid venoms by Eclipta prostrata (Asteraceae) extracts and constituents. Toxicon. 32, 595-603.

Melo, P.A., and Ownby, C.L. (1996) Different sensitivity of fast- and -slow twitch muscles to some snake venoms and myotoxins. Toxicon 34, 653-669.

Ownby, C.L. (1982) Pathology of rattlesnake envenomation. In: Rattlesnake Venoms: Their Actions and Treatments (Tu, A.T., Ed). New York: Marcel Dekker, Inc., pp. 163-210.

Ownby, C.L. (1990) Locally acting agents: myotoxins, hemorrhagic toxins and dermonecrotic factors. In: Handbook of Toxinology. Shier, W.T. and Mebs, D., (Eds.), New York: Marcel-Dekker. pp. 602-654.

Ownby, C.L., Tu, A.T. and Kainer, R.A. (1975) Effect of diethylenetriaminepentacetic acid and procaine on hemorrhage induced by rattlesnake venom. J. Clin. Pharm. 15, 419-426.

Ownby, C.L., Cameron, D., and Tu, A.T. (1976) Isolation of a myotoxic component from rattlesnake (Crotalus viridis viridis) venom. J. Am. Path. 85, 149-158.

Ownby, C.L. and Tu, A.T. (1977) Chemical neutralization of snake venoms. In: Venoms: Chemistry and Molecular Biology. Tu, A.T. (Ed). New York: John Wiley and Sons, Inc.

Ownby, C.L., Bjarnason, J.W. and Tu, A.T. (1978) Hemorrhagic toxins from rattlesnake $(C$. atrox) venom. Pathogenesis of hemorrhage induced by three purified toxins. Am. J. Pathol. 93, 201-218. 
Ownby, C.L., Gutierrez, J.M., Colberg, T.R., and Odell, G.V. (1982) Quantitation of myonecrosis induced by myotoxin a from preirie rattlesnake (Crotalus viridis viridis) venom. Toxicon 20, 877-885.

Ownby, C. L., Odell, G. V., Woods, W. M. and Colberg, T. R. (1983) Ability of antiserum to myotoxin-a from prairie rattlesnake (Crotalus viridis viridis) to neutralize local myotoxicity and lethal effects of myotoxin and homologous crude venom. Toxicon 21, 35-45.

Ownby, C.L., Colberg, T.R., and Odell, G.V. (1984) A new method for quantitating hemorrhage induced by rattlesnake venoms: ability of polyvalent antivenom to neutralize hemorrhagic activity. Toxicon. 22, 227-233.

Ownby, C.L., Colberg, T.R., and Odell, G.V. (1985) Ability of a mixture of antimyotoxin a serum and polyvalent (Crotalidae) antivenin to neutralize myonecrosis, hemorrhage and lethality induced by prairie rattlesnake (Crotalus viridis viridis) venom. Toxicon 23, 317-324.

Ownby, C.L., Colberg, T.R., and Odell, G.V. (1986) In vivo ability of antimyotoxin a serum plus polyvalent (Crotalidae) antivenom to neutralize prairie rattlesnake (Crotalus viridis viridis) venom. Toxicon 24, 197-200.

Ownby, C.L., and Colberg, T.R. (1987) Characterization of the biological and immunological properties of fractions of prairie rattlesnake (Crotalus viridis viridis) venom. Toxicon 25, 1329-1342.

Ownby, C.L., and Colberg, T.R. (1988) Classification of myonecrosis induced by snake venoms: venoms from the prairie rattlesnake (Crotalus viridis viridis), western diamondback (Crotalus atrox) and the Indian cobra (Naja naja naja). Toxicon 26, 459-474. 
Ownby, C.L., Colberg, T.R., and White, S.P. (1997) Isolation, characterization, and crystallization of a PLA ${ }_{2}$ myotoxin from the venom of the Prairie Rattlesnake (Crotalus viridis viridis). Toxicon 35, 111-124.

Ohsaka, A., Suzuki, K., and Ohashi, M. (1975) The spurting of erythrocytes through junctions of the vascular endothelium treated with snake venoms. Microvasc. Res. 10, 208-213.

Parrish H. M., Silberg S. L. and Goldner J. C. (1965) Snakebite: A pediatric problem. Clin Pediatr. 4, 237-241.

Queiroz, L.S., Santo Neto, H., Assakura, M., Reichl, A.P. and Mandelbaum, F.R. (1985) Pathological changes in muscle caused by haemorrhagic and proteolytic factors from Bothrops jararaca snake venom. Toxicon, 23, 341-345.

Reid, H.A., Thean, P.C., and Martin, W.J. (1963) Specific antivenene and prednisone in viper-bite poisoning: controlled trial. Br. Med. J. II: 1378-1380.

Riviere, G., Choumet, V., Audebert, F., Sabouraud, A., Debray, M., Scherrmann, J.M., Bon, C. (1997) Effect of antivenom on venom pharmacokinetics in experimentally envenomated rabbits: toward an optimization of antivenom therapy. J. Pharm. Exp. Ther. 281, 1-8.

Rucavado, A., and Lomonte, B. (1996) Neutralization of myonecrosis, hemorrhage, and edema induced by Bothrops asper snake venom by homologous and heterogenous pre-existing antibodies in mice. Toxicon. $\mathbf{3 4}$, 567-577.

Russell, F.E., Ruzic, N., and Gonzalez, H. (1973) Effectiveness of antivenin (Crotalidae) polyvalent following injection of Crotalus venom. Toxicon 11, 461464. 
Russell, F.E. (1983) Identification and distribution of North American poisonous snakes. Snake Venom Poisoning. Scholium International, Great Neck, N.Y.

Russell, F.E. (1996) Snake venom poisoning in the United States of America. In: Envenomings and Their Treatments, Bon, C. and Goyffon, M. (Eds). Pasteur Institute, Paris, pp. 235-246.

Sherrmann, J.M. and Pepin, S. (1996) Biodynamics of antigen-antibody neutralization in vivo. In: Envenomings and Their Treatments, Bon $\mathrm{C}$ and Goyffon M (Eds). Pasteur Institute, Paris, pp. 109-116.

Snyder, C.C. (1991) Snakebite treatment by plastic surgery application. In: Handbook of Natural Toxins, Vol. 5, Reptile Venoms and Toxins, Tu, A.T.(Ed.). New York: Marcel Dekker. pp. 645-686

Stocker, K.F. (1990) The Medical Uses of Snake Venom Proteins. Boca Raton: CRC Press.

Sutherland, S., Coulter, A., and Harris, R. (1979) Rationalization of first aid measures for elapid snake bite. Lancet 1, 183-186.

Swaroop, S. and Grab, B. (1954) Snakebite mortality in the world. Bull. W H. O. 10, 35-76.

Takeya, H., Oda, K., Miyata, T., Omori-Satoh, T. (1990) The complete amino acid sequence of the high molecular mass hemorrhagic protein HRB1 isloated from the venom of Trimeresurus flavoviridis. J. Biol. Chem., 265, 16068-16073. 
Theakston, R.D.G. (1996) Snake bite: the kinetics of envenoming and therapy. In: Envenomings and Their Treatments, Bon, C. and Goyffon, M. (Eds). Pasteur Institute, Paris, pp. 117-126.

Tu, A.T. (1977) Venoms: Chemistry and Molecular Biology. New York: John Wiley and Sons, Inc.

Tu, A.T. (1982) Chemistry of rattlesnake venoms. In: Rattlesnake Venoms, their actions and treatments, Tu, A.T. (Ed). New York: Macel Dekker. pp. 247-299.

Tu, A.T. and Homa, M. (1970) Toxicologic study of snake venoms from Costa Rica. Toxicol. Appl. Pharmacol. 16, 73-78.

Tu, A.T. (1991) Tissue damaging effects by snake venoms: hemorrhage and myonecrosis. In: Handbook of Natural Toxins, Vol. 5, Reptile Venoms and Toxins, Tu, A.T. (Ed.). New York: Marcel Dekker. pp. 297-348.

Underwood, G. (1979) Classification and distribution of venomous snakes in the world. In: Snake Venoms. Handbook of Experimental Pharmacology, Vol. 52, Lee, C.Y. (Ed). Springer-Veriag, Berlin: pp. 15-40.

Volwerk, J.J., Pieterson, W. A., and de Haas, G.H. (1974) Histidine at the active site of phospholipase $A_{2}$. Biochemistry 13, 1446-1454.

Warrell, D.A. and Fenner, P.J. (1993) Venomous bites and stings. Br. Med. Bull. 49, 423-439.

Warrell, D.A .(1996) Clinical features of envenoming from snakebites. In: Envenomings and Their Treatments, Bon, C. and Goyffon, M. (Eds). Pasteur Institute, Paris, pp. 63-76. 
Warrell, D.A. (1995) Clinical toxiclogy of snake bite in Asia. In: Handbook of Clinical Toxicology of Animal Venoms and Poisons. Meier, J. and White. J. (Eds). CRC Press, Boca Raton, pp. 493-594.

White, J. (1995) Poisonous and venomous animals - a physicians's view. In: Handbook of Clinical Toxicology of AnimalVenoms and Poisons. Meier, J. and White, J. (Eds). CRC Press, Boca Raton, pp. 9-26.

Wingert, W.A. (1991) Management of Crotalid envenomations. In: Handbook of Natural Toxins, Vol. 5, Reptile Venoms and Toxins, Tu, A.T. (Ed.). New York: Marcel Dekker. pp. 611-644

Weissenberg, S., Ovadia, M., and Kochva, E. (1987) Species specific sensitivity towards the hemorrhagin of Ophiophagus hanna (Elapidae). Toxicon 25, 475481. 


\author{
VITA \\ Jason Evans \\ Candidate for the Degree of \\ Master of Science
}

Thesis: NEUTRALIZATION OF EDEMA, HEMORRHAGE AND MYONECROSIS INDUCED BY NORTH AMERICAN CROTALID VENOMS IN SIMULATED FIRST-AID TREATMENTS

Major Field: Physiological Science

Biographical:

Personal Data: Born in Scottsdale, Arizona, On March 14, 1973, the son of Robert J. Evans, Jr. and Sherry (and Bruce) Pierce.

Education: Graduated from Cornado High School, Scottsdale, Arizona in June 1991; received Bachelor of Science degree in Physiology with a minor in English Literature from Oklahoma State University, Stillwater, Oklahoma in May 1996. Currently enrolled in the Doctor of Veterinary Medicine program at College of Veterinary Medicine, Oklahoma State University, Stillwater, Oklahoma to be completed in May 1999. Completed the requirements for the Master of Science degree with a major in Physiological Science at Oklahoma State University in December 1997.

Experience: Raised in Scottsdale, Arizona; Spent a summer internship at Fermilab National Particle Accelerator Laboratory. Employed by Oklahoma State University, Department of Zoology as an undergraduate as a research assistant working on herpetological population studies, 1993 to 1995.

Professional Memberships: Student Chapter of the American Veterinary Medical Association, Veterinary Emergency and Critical Care Society, American Association of Feline Practitioners, International Society of Toxinologists. 